\section{Pulmonary Aspergillosis in a Child with Hyperimmunoglobulin E Syndrome}

Pulmonary aspergillosis is uncommon in childhood but may be encountered in immunocompromised patients. Hyperimmunoglobulin $\mathrm{E}$ syndrome (HIE) is characterized by marked elevation in the level of immunoglobulin $\mathrm{E}$ and recurrent deep-seated infections. We describe a patient with HIE who developed an aspergilloma in the upper lobe of the right lung. Although Staphylococcus aureus, other gram-positive and gram-negative organisms, and Candida species have frequently been isolated from patients with HIE syndrome, infections with Aspergillus species occur very rarely in these patients [1].

A 15-year-old boy was admitted to the pediatric ward with a 2-day history of cough followed by chest pain and dyspnea. His medical history was characterized by several episodes of pneumonia, suppurative otitis media, salmonella sepsis, staphylococcal skin infections, and "cold" abscesses. He had coarse facies and pruritic dermatitis. Two years before presentation, he had had cryptococcal meningitis that resolved only after he had received prolonged specific antifungal therapy and a permanent myeloperitoneal shunt had been inserted because of increased intracranial pressure.

On admission, the patient's temperature was $37.2^{\circ} \mathrm{C}$; pulse, 70/min; respirations, 40/min; and blood pressure, 120/75 mm Hg. He had mild peripheral and perioral cyanosis. Breath sounds over the right hemithorax were reduced, without wheezing or crepitations. Findings of the remainder of the physical examination were unremarkable.

Laboratory studies revealed the following values: erythrocyte sedimentation rate, $80 \mathrm{~mm} / \mathrm{h}$; hemoglobin, $14.7 \mathrm{~g} / \mathrm{dL}$; WBCs, $9,000 / \mathrm{mm}^{3}$ (67\% neutrophils, $21 \%$ lymphocytes, $8 \%$ monocytes, and $4 \%$ eosinophils); and platelets, $267,000 / \mathrm{mm}^{3}$. Cultures of blood, urine, and sputum were all negative. A tuberculin test with 5 units of PPD was negative. Chest radiographs showed right pneumothorax with right lung atelectasis. The serum IgE level was 20,000 IU/mL (normal level, 50-150 IU/mL), and the IgG level was 2,033 $\mathrm{mg} / \mathrm{dL}$ (normal level, 600-1,800 $\mathrm{mg} / \mathrm{dL}$ ). The results of other humoral and cellular immunity studies were normal. The neutrophil chemotactic activity was $40 \%$ of the normal control.

A thoracic drain was placed, which resulted in expansion of the right lung. However, pneumothorax recurred on each of three attempts to remove the drain. The patient was treated with cloxacillin (4 g/d), ceftazidime (4 g/d), and amikacin (800 $\mathrm{mg} / \mathrm{d}$ ) for 10 days, but his condition did not improve. A CT scan of the chest showed right pneumothorax, thickening of the pleural walls, and a right upper-lobe cavitation, compatible with the presence of a fungus ball (figure 1). Bronchoscopy was performed, followed by right upper lobectomy. A culture of tissue from the cavity yielded Aspergillus fumigatus. Histopath-

Reprints or correspondence: Dr. B. Wolach, Department of Pediatrics, Meir General Hospital, 44281 Kfar Saba, Israel.

Clinical Infectious Diseases 1998;26:204-5

(C) 1998 by The University of Chicago. All rights reserved

$1058-4838 / 98 / 2601-0043 \$ 03.00$

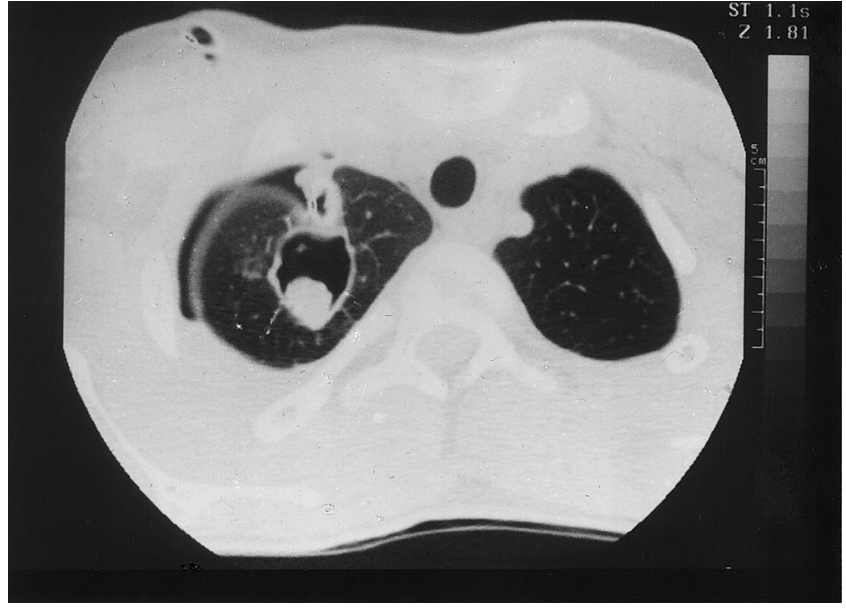

Figure 1. CT scan of the chest of a patient with pulmonary aspergillosis and hyperimmunoglobulin E syndrome shows right lung pneumothorax and a thickened cyst wall in the right upper lobe.

ological examination showed lymphocytic interstitial infiltration with foam and giant cells in the alveolar sacs and pleura and fibrosis of alveolar walls. The patient was treated with itraconazole for 3 months. There were no postoperative complications.

Although candida infections are relatively common in patients with HIE syndrome, aspergillus infections are extremely rare [1]. To our knowledge, only one adult with HIE syndrome and an aspergilloma has been described [2]. Aspergillus species can produce a wide spectrum of pulmonary diseases, ranging from invasive disease in severely immunosuppressed patients to hypersensitivity reaction, such as allergic bronchopulmonary aspergillosis, in atopic patients [3].

Bronchial pulmonary aspergillosis may be asymptomatic, but when it is symptomatic, it usually presents as hemoptysis, chronic cough, and, less commonly, weight loss [4]. This infection tends to occur in patients with chronic lung disease; the most common underlying disease is tuberculosis.

Patients with bronchial aspergillomas are younger and have better nutritional statuses and respiratory functions than patients who have pulmonary and pleural lesions [5].

Even though our patient had recurrent pneumonia, he did not have apparent chronic lung disease. He presented with cough, pleuritic pain, and pneumothorax - a rare presentation. A. fumigatus was isolated from the cavitation, and the pleura was involved in the disease. Despite the complicated course of cryptococcal meningitis in this immunocompromised patient, he did not develop invasive aspergillosis.

There is no consensus that surgery is mandatory for treatment of aspergilloma, but surgical treatment of pulmonary or pleural aspergilloma is recommended for patients with recurrent severe hemoptysis or life-threatening symptomatic manifestations [5, 6]. Postoperative outcome is much better for patients with bronchial aspergilloma than for those with pulmonary and pleural aspergilloma [7]. The operative risk is low for patients who are asymptomatic and have no underlying lung disease. Our patient was considered at high operative risk because of his immunocompromised status and pleuropulmonary involvement. On the other hand, he 
was young, had good nutritional status, and had no underlying lung disease, and the lesion was well circumscribed in the right upper lobe.

Patients with inoperable aspergillomas or those with invasive aspergillosis may be treated satisfactorily with amphothericin B or a combination of amphothericin B and 5-flucytosine. Recent studies have described successful treatment of invasive aspergillosis with lyposomal amphothericin B [8] and itraconazole $[9,10]$.

\section{Baruch Wolach, Alon Eliakim, Giora Gottesman, and Alon Yellin} Department of Pediatrics, Sapir Medical Center, Meir General Hospital, Kfar Saba; and Department of Thoracic Surgery, Sheba Medical Center, Tel Hashomer, Tel-Aviv University Sackler School of Medicine, Tel-Aviv, Israel

\section{References}

1. Leung DY, Geha RS. Clinical and immunologic aspects of hyperimmunoglobulin E syndrome. Hematol Oncol Clin North Am 1988;2:81-100.

\section{Candida Endocarditis Following Percutaneous Transluminal Coronary Angioplasty}

Although percutaneous transluminal coronary angioplasty (PTCA) is performed frequently, to our knowledge, it has not been associated with subsequent serious infection. We report a case of candida endocarditis that occurred after PTCA was performed.

A 42-year-old female was admitted to the hospital with a 4-month history of fever. Five months before admission, she had undergone emergent PTCA twice at a local hospital because of acute myocardial infarction involving the right coronary artery. She was discharged after 1 week of hospitalization. Two weeks later, she developed intermittent fever (temperature, $\leqslant 39^{\circ} \mathrm{C}$ ) in association with dizziness, black floaters, soreness over her right leg, and pain on pressure over her nails.

She was readmitted to the same hospital because of the persistent fever, soreness over her right leg, and painful nails. Blood cultures yielded Candida species, and nosocomial fungemia was diagnosed. Oral fluconazole was prescribed at a dose of $100 \mathrm{mg} / \mathrm{d}$, and she was discharged 3 weeks later with instructions to continue taking oral fluconazole. The fever and the symptoms of painful nails and right leg soreness subsided during hospitalization but recurred 2 days after discharge. The fever persisted despite the fact that the

Reprints or correspondence: Dr. Jen-Hsien Wang, Section of Infectious Diseases, Department of Internal Medicine, Veterans General Hospital-Kaohsiung, 386 Ta-Chung 1st Road, Kaohsiung, Taiwan 813, Republic of China.

Clinical Infectious Diseases 1998;26:205-6

(C) 1998 by The University of Chicago. All rights reserved.

$1058-4838 / 98 / 2601-0044 \$ 03.00$
2. Hall RA, Salhany KE, Lebel E, Bavaria JE, Kaiser LR. Fungal pulmonary abscess in an adult secondary to hyperimmunoglobulin E syndrome. Ann Thorac Surg 1995; 59:759-61.

3. Gefter WB. The spectrum of pulmonary aspergillosis. J Thorac Imaging 1992; 7:56-74.

4. Etienne T, Spiliopoulos A, Megevand R. Pulmonary aspergilloma. Helv Chir Acta 1990; 57:337-42.

5. Massard G, Roeslin N, Wihlm JM, Dumont P, Witz JP, Morand G. Pleuropulmonary aspergilloma: clinical spectrum and results of surgical treatment. Ann Thorac Surg 1992;54:1159-64.

6. Glimp RA, Bayer AS. Pulmonary aspergilloma. Diagnostic and therapeutic considerations. Arch Intern Med 1983;143:303-8.

7. Daly RC, Pairolero PC, Piehler JM, Trastek VF, Payne WS, Bernatz PE. Pulmonary aspergilloma: results of surgical treatment. J Thorac Cardiovasc Surg 1986;92:981-8.

8. Richards EM, Apperley JF, Marcus RE. Successful use of lyposomae encapsulated amphothericin to treat invasive aspergillosis following failure of conventional amphothericin. Clin Lab Haematol 1992;14: $127-30$.

9. Dupont B. Itraconazole therapy in aspergillosis: study of 49 patients. J Am Acad Dermatol 1990;23:607-14.

10. Milleron B, Roger V, Roux P, et al. Semi-invasive aspergillosis with involvement of the thoracic wall cured by itraconasole. Rev Pneumol Clin 1990; 46:175-7.

fluconazole dose was increased to $200 \mathrm{mg} / \mathrm{d}$; thus, she was referred to our hospital for further care.

Physical examination on admission revealed fever (temperature, $38.6^{\circ} \mathrm{C}$ ) and tachycardia without any peripheral embolic signs in the eyes and oral cavity. The heartbeat was regular, with a splitting of $\mathrm{S}_{1}$; a grade $2 / 6$ systolic murmur was heard over the right and left upper sternal borders, with radiation to the neck. The chest was clear without basal rales. Splinter hemorrhagic spots were found on the right 2nd and 4th fingers and the left 3rd finger, and Janeway lesions were seen over both palms. The right leg was cold and tender to palpation, and the right pedal pulse was diminished. Findings of the remainder of the physical examination were unremarkable.

Four sets of cultures of blood obtained at admission all yielded Candida parapsilosis. A transthoracic echocardiogram showed vegetations on the aortic valves, which were associated with mild aortic regurgitation and mitral regurgitation. Left aortoiliac embolization was disclosed by a Doppler study of the lower extremities. Therapy with intravenous amphotericin B $(0.5 \mathrm{mg} / \mathrm{kg})$ was initiated immediately on admission, and therapy with oral fluconazole was discontinued.

Aortic valve replacement with a mechanical valve (Carbomedics, Austin, TX) and left aortoiliac embolectomy were performed on the 7th hospital day. Large vegetations were found over all three leaflets of the aortic valve, but there was no significant aortic valvular dilatation. Culture of the valve tissue yielded C. parapsilosis and Candida albicans.

Intravenous amphotericin B was administered postoperatively at a dose of $0.5 \mathrm{mg} /(\mathrm{kg} \cdot \mathrm{d}$ ) (total dose, $1,020 \mathrm{mg}$ ). The patient's postoperative clinical course was uncomplicated, and she was discharged and instructed to take oral fluconazole at a dose of 200 $\mathrm{mg} / \mathrm{d}$. Inflammatory activity was monitored by obtaining monthly measurements of the erythrocyte sedimentation rate (ESR) and 
the C-reactive protein (CRP) level. Two months after discharge, progressive elevation of the ESR and CRP level occurred, but the patient did not have any symptoms. The dose of fluconazole was increased to $400 \mathrm{mg} / \mathrm{d}$ and was gradually tapered 4 months later. After receiving treatment for 1 year, she is well, and no relapses have occurred since therapy with fluconazole was discontinued.

PTCA is a frequently performed procedure for achieving repatency of coronary arteries in patients with ischemic heart disease. There have been no previous reports of any major infectious complications of PTCA. However, it is not difficult to envisage that damage to the endothelium may occur during PTCA; such damage is a predisposing factor for infective endocarditis. Candida species are normal flora of the skin and have been recognized as major pathogens in infections associated with indwelling catheters, and these organisms may very likely be associated with infections that occur after PTCA is performed. The mortality rate associated with candida endocarditis is lowest with combined medical and surgical treatment, rather than either medical or surgical treatment alone [1]. Immediate surgical intervention and treatment with amphoteri-

\section{Successful Treatment of Enterobacter Meningitis with Ciprofloxacin}

We recently encountered a patient who developed a postneurosurgical Enterobacter aerogenes-induced ventriculitis, which failed to respond to initial treatment with imipenem and subsequent treatment with trimethoprim-sulfamethoxazole (TMP-SMZ). However, there was a dramatic response and cure with ciprofloxacin. Although there have been two reports of the successful use of ciprofloxacin for treatment of ventriculitis due to Enterobacter species in infants $[1,2]$, to our knowledge, ours is the first report of successful treatment with ciprofloxacin for meningitis due to Enterobacter species in an adult.

A 38-year-old female was admitted to the hospital with sudden onset of severe retro-orbital pain, blurry vision, and neck stiffness. The patient underwent a neurological workup, which revealed a large subarachnoid hemorrhage; an arteriogram established the presence of a left vertebral artery aneurysm. A craniotomy with aneurysmal clipping was performed. Four days after surgery, the patient became unresponsive and febrile. A CT scan of the brain revealed edema and hydrocephalus. A ventriculostomy was performed that revealed cloudy CSF, and empirical therapy with ceftazidime and amikacin was started. Laboratory studies of the CSF revealed the following values: WBCs, $32,500 / \mathrm{mm}^{3}$ (with $95 \%$ polymorphonuclear leukocytes); RBCs, 3,100/ $\mathrm{mm}^{3}$; glucose, $18 \mathrm{mg} / \mathrm{dL}$ (peripheral blood level, $150 \mathrm{mg} / \mathrm{dL}$ ); and protein, $353 \mathrm{mg} / \mathrm{dL}$.

Cultures of CSF yielded E. aerogenes. The organism was susceptible to ciprofloxacin, gentamicin, TMP-SMZ, and imipenem and demonstrated intermediate susceptibility to cefotaxime and

Reprints or correspondence: Dr. Vincenzo Scotto D'Antuono, 2 Starsplitter Court, Voorhees, New Jersey 08043.

Clinical Infectious Diseases 1998;26:206-7

(C) 1998 by The University of Chicago. All rights reserved $1058-4838 / 98 / 2601-0045 \$ 03.00$ cin B are mandatory and life-saving. Because the incidence of relapse among patients with candida endocarditis is high, amphotericin B should be given for 6-10 weeks after surgery [2]. Despite such prolonged therapy, significant relapse rates may still be observed, even years after surgery. Suppressive fluconazole therapy may play an important role in the prevention of relapse; however, the optimal dosage and duration of such therapy are as yet undetermined and require further study.

Jen-Hsien Wang, Yung-Ching Liu, and Susan Shin-Jung Lee Section of Infectious Diseases, Department of Internal Medicine, Veterans General Hospital-Kaohsiung, Kaohsiung, Taiwan, Republic of China

References

1. Reyes MP, Lerner AM. Endocarditis caused by Candida species. In: Bodeg GP, Fainstein V, eds. Candidiasis. New York: Raven Press, 1985: 203-9.

2. Galgiani JN, Stevens DA. Fungal endocarditis: need for guidelines in evaluating therapy. J Thorac Cardiovasc Surg 1977;73:293-6.

ceftriaxone. The antibiotic regimen was changed to that with imipenem (750 mg q6h) and amikacin and intraventricular gentamicin. The patient remained febrile and comatose. The CSF pleocytosis abated initially; however, on the fourth day of therapy, the CSF culture was still positive. At that time, therapy with imipenem and amikacin was discontinued, and iv TMP-SMZ (5 mg/kg q6h) was begun, in combination with intraventricular gentamicin (10 mg daily).

The CSF culture became negative on the fourth day of therapy with TMP-SMZ and gentamicin, but the patient's neurological status remained unchanged. On the seventh day of iv TMP-SMZ and intrathecal gentamicin therapy, the CSF cell count revealed new pleocytosis (WBCs increased from 10 to $146,85 \%$ polymorphonuclear leukocytes), and the protein level was also increased (from 46 to $242 \mathrm{mg} / \mathrm{dL}$ ). The culture again yielded E. aerogenes.

TMP-SMZ and gentamicin therapy was discontinued, and the antibiotic regimen was changed to iv ciprofloxacin (400 $\mathrm{mg}$ b.i.d.); there was dramatic improvement in the patient's mental status with this therapy. Subsequent CSF cultures were negative. However, the patient's mental status never completely normalized; thus, a ventriculo-peritoneal shunt was eventually placed, and she was discharged to a long-term care facility. Levels of ciprofloxacin in the CSF were never determined; the MIC of ciprofloxacin for the isolate was $0.14 \mu \mathrm{g} / \mathrm{mL}$.

Gram-negative bacillary meningitis is a disease seen primarily in neurosurgical patients [3] and neonates [4]. Before the development of third-generation cephalosporins, treatment of this condition was difficult because many antibacterial agents could not achieve concentrations in the CSF sufficient to sterilize it. To solve this problem, intrathecal instillation of aminoglycosides has been used [5]. However, this procedure produces undesirable side effects, and the lower $\mathrm{pH}$ of purulent CSF decreases aminoglycoside activity. In addition, there is considerable risk for superinfection with daily instillation of aminoglycosides into the CSF.

The treatment of gram-negative bacillary meningitis has been facilitated with use of the third-generation cephalosporins since they are very active against gram-negative organisms and penetra- 
tion into the CSF is excellent [6]. However, causative organisms (Escherichia coli, Klebsiella pneumoniae, Pseudomonas aeruginosa, Acinetobacter calcoaceticus, and Enterobacter cloacae) are often acquired nosocomially and typically are resistant to multiple agents, as was the case in our patient.

Other agents that may be useful in the treatment of gramnegative bacillary meningitis include imipenem, TMP-SMZ, and ciprofloxacin. The use of TMP-SMZ has been emphasized as therapy for gram-negative bacillary meningitis caused by Enterobacter species [7]. Ciprofloxacin has been shown to enter the CSF at levels $6.5 \%-39 \%$ of the serum levels observed in patients with bacterial meningitis [8].

In 1989, Schonwald [9] reported effective treatment with ciprofloxacin in a group of 20 patients with gram-negative bacillary meningitis. E. coli was the most common isolate. Only one patient had meningitis due to Enterobacter species, and the specifies of this case were not revealed so it was not clear if this patient failed to respond to treatment [9]. The MICs of ciprofloxacin for the causative agents were determined and were found to be very low, as in our case.

Newer agents such as cefipime and meropenem, although not used in our patient, could have been used. Cefipime may have higher activity than the third-generation cephalosporins against E. aerogenes and has been shown to be clinically successful in the treatment of infants and children with meningitis caused by common pathogens. However, there are no clinical data yet available with respect to treatment with cefipime in adults with meningitis due to common pathogens or nosocomial gram-negative rods. Meropenem may have increased activity over imipenem for the treatment of infection due to E. aerogenes, and meropenem appears to have a lower propensity for causing seizures than imipenem. In addition, there are clinical data demonstrating the efficacy of meropenem for treatment of meningitis caused by

\section{Elevation of Platelet Counts Associated with Indinavir Treatment in Human Immunodeficiency Virus-Infected Patients}

Thrombocytopenia is a common manifestation of HIV infection. There appear to be two distinct mechanisms responsible for thrombocytopenia in HIV infection; immune-mediated destruction of platelets and a defect in platelet production due to direct infection of the megakaryocyte [1]. Platelet sequestration and immunemediated destruction appear to be more important early in HIV infection, whereas decreased platelet production appears to be predominant in the advanced stages of AIDS [2]. Severe thrombocytopenia is accompanied by a risk of bleeding, and treatment of thrombocytopenia is recommended when platelet counts decrease to a

Reprints or correspondence: Dr. Thomas E. Coyle, Regional Oncology Center, SUNY HSC at Syracuse, 750 East Adams Street, Syracuse, New York 13210.

Clinical Infectious Diseases 1998;26:207-8

(C) 1998 by The University of Chicago. All rights reserved $1058-4838 / 98 / 2601-0046 \$ 03.00$ common pathogens in adults, as well as meningitis due to Pseudomonas species [10].

In conclusion, if the isolate is resistant to $\beta$-lactams, then the drug of choice may be TMP-SMZ for treatment of enterobacter meningitis. Ciprofloxacin may be an alternative agent if the isolate is susceptible and the MIC is low. Further randomized studies are needed to compare the efficacy of ciprofloxacin with standard agents and newer agents that can be used to treat this disease.

Vincenzo Scotto D'Antuono and Irving Brown

Department of Infectious Diseases, Robert Wood Johnson University Hospital, New Brunswick, New Jersey

\section{References}

1. Goepp JG. Use of Ciprofloxacin in an infant with ventriculitis. J Pediatr $1992 ; 121: 303-5$.

2. Bannon MJ. Ciprofloxacin in neonatal Enterobacter cloacae septicemia. Arch Dis Child 1989; 64:1388.

3. Buckwold FJ. Hospital acquired bacterial meningitis in neurosurgical patients. J Neurosurg 1977; 46:494-500.

4. Rossomando E. Bacterial meningitis. Review of the literature and retrospective study of 208 cases observed. Minerva Pediatr 1994; 46: $193-200$.

5. Corrado ML. Designing appropriate therapy in the treatment of gram negative bacillary meningitis. JAMA 1982;248:71-4.

6. Cunha BA. Third generation cephalosporins: a review. Clin Ther 1992; 14:616-52.

7. Wolff MA, Young CL, Ramphal R. Antibiotic therapy for enterobacter meningitis: a retrospective review of 13 episodes and review of the literature. Clin Infect Dis 1993; 16:772-7.

8. Barsic B. Entry of Ciprofloxacin into cerebrospinal fluid during bacterial, viral and tuberculous meningitis. Neurologia Croatica 1991;40:111-6.

9. Schonwald S. Brief report: Ciprofloxacin in the treatment of gram negative bacillary meningitis. Am J Med 1989; 87:248S-249S.

10. Med Lett Drugs Ther 1996;38(983, 984):84-86, 88-90. level of $\leqslant 30 \times 10^{9} / \mathrm{L}$ [3]. Glucocorticoids and splenectomy have been the usual initial treatments. Treatment with zidovudine has also been associated with an elevation in platelet counts [4] and platelet production [5] in both thrombocytopenic and nonthrombocytopenic HIV-infected patients; this agent has been recommended as the initial treatment of choice by some authors [6]. On the basis of these considerations, we hypothesized that because of its potent antiretroviral activity, treatment with a protease inhibitor would be associated with an abatement of thrombocytopenia, particularly in patients with advanced AIDS.

To test the hypothesis that indinavir treatment, as a component of triple antiretroviral therapy, is associated with elevation of platelet counts, we performed a single-center retrospective analysis of HIV-infected patients treated with indinavir at Designated AIDS Care Center and the Comprehensive Hemophilia Treatment Center of the SUNY Health Science Center at Syracuse. Inclusion criteria were as follows: documented HIV positivity; indinavir treatment for at least 2 weeks, and platelet counts available within 2 months before initiation of indinavir treatment and for at least 2 weeks after the initiation of therapy. Patients were excluded if they started receiving zidovudine therapy concurrently, if noncompliance with their medications had been documented, if they were receiving other treatment for thrombocytopenia, or if they were receiving 
Table 1. Effects of indinavir on platelet counts of thrombocytopenic and nonthrombocytopenic HIV-seropositive patients.

\begin{tabular}{lccc}
\hline & \multicolumn{2}{c}{ Platelet counts $\left(\times 10^{9} / \mathrm{L}\right)$} & \\
\cline { 2 - 3 } & $\begin{array}{c}\text { Preindinavir } \\
\text { treatment }\end{array}$ & $\begin{array}{c}\text { Postindinavir } \\
\text { treatment }\end{array}$ & $P$ value \\
\hline $\begin{array}{l}\text { Thrombocytopenic } \\
(n=18)\end{array}$ & $117(86-145)$ & $173(95-302)$ & .0002 \\
$\begin{array}{c}\text { Nonthrombocytopenic } \\
(n=44)\end{array}$ & $240(155-402)$ & $252(142-482)$ & .10 \\
$\begin{array}{c}\text { Total } \\
(n=62)\end{array}$ & $204(86-402)$ & $229(95-482)$ & .001 \\
\hline
\end{tabular}

NOTE. Data are presented as mean (range).

other protease inhibitors concurrently. Data collected included general demographics, previous antiretroviral treatments, platelet counts $0-2$ months before initiation of indinavir treatment and all counts after the start of treatment, and absolute CD4 cell counts before initiation of indinavir therapy. HIV viral loads were not available for the majority of these patients.

Data were evaluated by comparing the last platelet count before commencing indinavir therapy and the first count obtained $\geqslant 2$ weeks after initiation of treatment in each patient. The one-tailed Student's $t$ test for paired samples was used to evaluate the data for all patients included in the study as well as for a subgroup of patients identified as thrombocytopenic, defined as having preindinavir platelet counts of $<150 \times 10^{9} / \mathrm{L}$, and a subgroup comprising the remainder of the patients identified as nonthrombocytopenic. The two-tailed unpaired Student's $t$ test for samples of unequal variance was used to compare pretreatment absolute CD4 cell counts between the thrombocytopenic and nonthrombocytopenic groups.

Three hundred-forty charts were reviewed, and 62 patients met the inclusion criteria. All 62 patients received indinavir as part of a combination treatment regimen, which included zidovudine in 45 patients $(73 \%)$. The mean duration of prior zidovudine therapy was 15.7 months (range, 1-82 months). The mean times for obtaining the preindinavir platelet counts and postindinavir platelet counts were 1 month (range, 0-2 months) before the start of protease inhibitor treatment and 2 months (range, $0.5-8$ months) after the start of treatment, respectively.

The results are summarized in table 1 . The mean increase in platelet counts for both patient groups was $25 \times 10^{9} / \mathrm{L}$ (range,
-131 to $\left.+217 \times 10^{9} / \mathrm{L}\right)$. Eighteen patients were thrombocytopenic. Platelet counts increased for each of the 18 patients, from preto postindinavir treatment, a mean increase of $56 \times 10^{9} / \mathrm{L}$ (range, $\left.6-183 \times 10^{9} / \mathrm{L}\right)$. The mean increase in pre- to postindinavir platelet counts for the 44 nonthrombocytopenic patients was $12 \times 10^{9} / \mathrm{L}$ (range, -131 to $+217 \times 10^{9} / \mathrm{L}$ ); this difference was not statistically significant. There was a decrease in platelet counts for 20 nonthrombocytopenic patients and an increase for 24 of those patients. The mean absolute CD4 cell count for the thrombocytopenic group was $64 / \mu \mathrm{L}$ (range, $10-290 \mu \mathrm{L}$ ), as compared to $176 / \mu \mathrm{L}$ (range, $10-650 \mu \mathrm{L}$ ) for the nonthrombocytopenic group $(P<.01)$.

We conclude that initiation of antiretroviral treatment with indinavir as part of combination therapy is associated with an increase in platelet counts in patients with mild-to-moderate thrombocytopenia due to HIV infection. Patients with thrombocytopenia appeared to have more advanced disease, as evidenced by lower absolute CD4 cell counts. Because indinavir therapy did not increase the platelet count in nonthrombocytopenic patients significantly, these observations suggest that indinavir may increase the platelet count through its antiretroviral effects, rather than by a nonspecific mechanism. The data obtained from our study provide the rationale for a prospective trial of indinavir as part of combination antiretroviral therapy for patients with thrombocytopenia and advanced HIV infection.

Lori J. Maness, Donald C. Blair, Nancy Newman, and Thomas E. Coyle

SUNY Health Science Center at Syracuse, Syracuse, New York

\section{References}

1. Coyle TE. Hematologic complications of HIV infection and the acquired immunodeficiency syndrome. Med Clin North Am 1997; 81:449-70.

2. Najean Y, Rain JD. The mechanism of thrombocytopenia in patients with HIV infection. J Lab Clin Med 1994; 123:415-20.

3. Landonio G, Nosari A, Spinelli F, Vigorelli R, Caggese L, Schlacht I. HIVrelated thrombocytopenia: four different clinical subsets. Haematologica 1992; 77:398-401.

4. Montaner JS, Le T, Fanning M, et al. The effect of zidovudine on platelet count in HIV-infected individuals. J Acquir Immune Defic Syndr 1990; 3:565-70

5. Ballem PJ, Belzberg A, Devine DV, Lyster D, Spruston B, Chambers H. Kinetic studies of the mechanism of thrombocytopenia in patients with human immunodeficiency virus infection. N Engl J Med 1993;327: 1779-84.

6. Oksenhendler E, Selimann M. HIV-related thrombocytopenia. Immunodefic Rev 1990;2:221-31. 


\section{Occult Cytomegalovirus Infection of Marrow Stroma}

A 50-year-old cytomegalovirus (CMV)-seropositive male with chronic myelogenous leukemia in blast crisis received an unrelated, one-antigen mismatched marrow transplant at a dose of $5.2 \times 10^{8}$ cells $/ \mathrm{kg}$. The patient was conditioned with 120 $\mathrm{mg} / \mathrm{kg}$ cyclophosphamide and 1,350 cGy of total body irradiation. He received methotrexate and cyclosporine as prophylaxis for graft-versus-host disease, and engraftment occurred on posttransplantation day 21. On day 61 he became CMV pp65 antigen positive, and treatment with ganciclovir $(5 \mathrm{mg} / \mathrm{kg}$ every 12 hours for 7 days followed by $5 \mathrm{mg}[\mathrm{kg} \cdot \mathrm{d}], 6$ days per week) was initiated. Therapy with granulocyte-colony stimulating factor (G-CSF) was started on day 76 in response to a decline in the absolute neutrophil count (ANC).

Serum became negative for antigenemia by day 103 , and ganciclovir therapy was discontinued; however, the ANC continuously declined, and the marrow cellularity dropped from $100 \%$ on day 125 to $33 \%$ on day 137 . All cells were of donor origin, and there was no evidence of relapse. The patient's CMV blood culture and pp65 antigenemia test were negative at this time. However, the day-137 marrow sample tested positive by use of PCR for CMV DNA, and cultured marrow stromal cells expressed viral antigen and shed virus (figure 1). Consequently, treatment with iv foscarnet ( $60 \mathrm{mg} / \mathrm{kg}$ every 8 hours), immunoglobulin ( $500 \mathrm{mg} / \mathrm{kg}$ every other day), and G-CSF was started on day 149. The ANC returned to normal, but the patient developed sinusitis due to Aspergillus species. Treatment with amphotericin B $(1 \mathrm{mg} /[\mathrm{kg} \cdot \mathrm{d}])$ was started on day 155 .

On day 159 , the patient developed bilateral infiltrates with increasing pp65 antigenemia. Culture of a bronchoalveolar lavage specimen yielded Candida albicans but was otherwise nondiagnostic. The patient died on posttransplantation day 165 of respiratory failure.

The potential etiologic role of CMV in this case of marrow suppression is supported by the presence of viral DNA in marrow and by the detection of immediate early and late CMV gene products in cultured marrow stroma. The absence of human herpes virus type 6 (HHV6) (another reportedly myelosuppressive virus) and the patient's hematopoietic response to specific antiviral treatment provide additional support that marrow suppression was most likely attributable to CMV. The fact that G-CSF, in combination with antiviral therapy, resulted in a rapid response agrees with the observation that G-CSF may be specifically downregulated in CMV-infected stroma [1].

CMV infection has long been associated with marrow suppression, but the documentation of virus in marrow cells from patients with marrow failure has been difficult to achieve. In the present

Grant support: This work was supported by the National Cancer Institute of the National Institutes of Health (CA18029, CA18221, DK34431, CA09515, and HL36444).

Reprints or correspondence: Dr. Beverly Torok-Storb, Fred Hutchinson Cancer Research Center, 1124 Columbia Street, M-318, Seattle, Washington 98104.

Clinical Infectious Diseases 1998;26:209-10

(C) 1998 by The University of Chicago. All rights reserved.

$1058-4838 / 98 / 2601-0047 \$ 03.00$

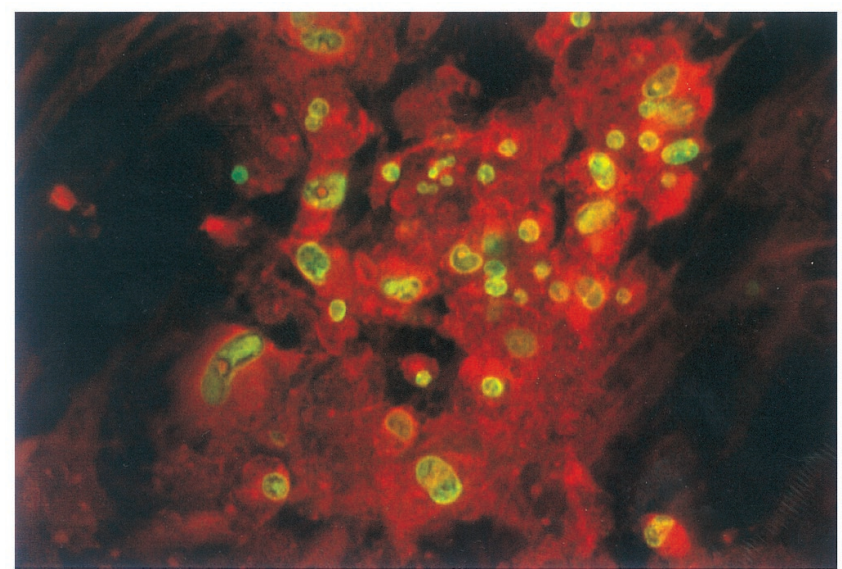

Figure 1. Detection of CMV gene products in stromal cells cultured from a marrow aspirate obtained on posttransplantation day 137 from a 50-year-old male. Adherent stromal cells were stained in situ by using a cocktail of fluoresceinated antibodies to CMV (green). The photomicrograph was obtained by use of an inverted fluorescence microscope with a direct camera attachment.

case, marrow suppression seems to have been caused by direct infection of cells in the marrow microenvironment. Findings on phase contrast microscopy of stromal cultures suggest that the infected cell is nonhematopoietic. The genotype of the CMV isolated from this patient encodes envelope glycoprotein B $(\mathrm{gB})$ type 4 ; this genotype is relatively rare, occurring in only $8 \%$ of renal transplant recipients and $9 \%$ of marrow transplant recipients $[2,3]$. The gB type may be significant, given a recent observation that myelosuppression after marrow transplantation is more significantly associated with gB types 3 and 4 than with types 1 and 2 [4]. The fact that CMV may be detected in marrow stroma in the absence of viremia or pp65 antigenemia is also in agreement with the results of a recent study by Rasmussen et al. [5], who showed that CMV gB4 is more common in sites other than leukocytes.

The observation that CMV-related myelosuppression can occur in the setting of low systemic viral load suggests that viral causes of marrow failure may be underdiagnosed and, further, that a diagnostic evaluation of marrow, including PCR analysis, is indicated for neutropenic patients with a history of positive CMV serology before transplantation. Given that poor marrow function can be fatal or can lead to secondary complications such as invasive fungal or bacterial infections, effective treatment should be started early.

\section{Michael Boeckh, Cynthia Hoy, and Beverly Torok-Storb Fred Hutchinson Cancer Research Center, and the University of Washington School of Medicine, Seattle, Washington}

References

1. Simmons P, Kaushansky K, Torok-Storb B. Mechanisms of a cytomegalovirus-mediated myelosuppression: perturbation of stromal cell function versus direct infection of myeloid cells. Proc Natl Acad Sci USA 1990; 87: $1386-90$. 
2. Chou S, Dennison KM. Analysis of interstrain variation in cytomegalovirus glycoprotein B sequences encoding neutralization-related epitopes. J Infect Dis 1991; 163:1229-34.

3. Fries BC, Chou S, Boeckh M, Torok-Storb B. Frequency distribution of cytomegalovirus envelope glycoprotein genotypes in bone marrow transplant recipients. J Infect Dis 1994;169:769-74.
4. Torok-Storb B, Boeckh M, Hoy C, Leisenring W, Myerson D, Gooley T. Association of specific cytomegalovirus (CMV) genotypes with death from myelosuppression after marrow transplantation. Blood 1997;90:2097-102.

5. Rasmussen L, Hong C, Zipeto D, et al. Cytomegalovirus gB genotype distribution differs in human immunodeficiency virus-infected patients and immunocompromised allograft recipients. J Infect Dis 1997; 175:179-84.

\section{Tuberculosis of the Thumb Following a Needlestick Injury}

Laboratory accidents involving needles and syringes are frequent and amount to almost one quarter of reported laboratory accidents [1]. The consequences can be dramatic and have become even more so since the arrival of the AIDS epidemic. We present a case of localized tuberculosis of the thumb that occurred after a laboratory accident.

At the end of February 1995, a 38-year-old male technician received a cervical lymph node for microbiological analysis. The specimen came from an HIV-positive, severely immunocompromized patient $\left(\mathrm{CD}^{+}\right.$lymphocyte count, $\left.40 / \mathrm{mm}^{3}\right)$ who had active pulmonary tuberculosis. A mycobacterial culture was requested.

In the laboratory, the lymph node was carefully ground, then decontaminated and inoculated into a radioactive BACTEC 12B bottle (Becton Dickinson, Cockeysville, MD) that was to be monitored at regular intervals in a BACTEC 460 TB instrument bottle (Becton Dickinson). An acid-fast stain of the specimen was strongly positive for acid-fast bacilli. After 10 days, the growth index of the bottle had reached the value of 60 , and the technician took a sample of a few milliliters of broth in a sterile syringe in order to inoculate a new BACTEC 12B bottle for a NAP ( $p$-nitro$\alpha$-acetylamino- $\beta$-hydroxypropiophenone) test. While trying to insert the needle through the membrane of the bottle, the technician stuck it deeply into the tip of his left thumb, touching the bone. $\mathrm{He}$ accidentally injected a bolus of the liquid deeply into his finger. Knowing about the risk of infection, he vigorously disinfected the wound with povidone-iodine. Despite the relatively low risk of contamination with HIV (the lymph node had been previously decontaminated, and it had been incubated for $>10$ days after removal), the technician was given prophylactic treatment with zidovudine ( $250 \mathrm{mg}$ b.i.d.) for 2 weeks. Tests for antibodies to HIV were negative at 0,3 , and 6 months.

Ten days later the technician felt numbness at the site of the former wound. He found that a pinhead-sized pustule on an erythematous base had replaced the punctiform lesion. He pierced the pustule with a lancet and observed numerous acid-fast bacilli in a Ziehl-Neelsen acid-fast stain.

The acid-fast bacilli in the lymph node were identified as Mycobacterium tuberculosis; susceptibility tests showed that the organisms were susceptible to the four principal antituberculous drugs-

Reprints or correspondence: Dr. Daniel Genné, Service de Médecine Interne, Hôpital de la ville, CH-2300 La Chaux-de-Fonds, Switzerland.

Clinical Infectious Diseases 1998;26:210-1

(C) 1998 by The University of Chicago. All rights reserved.

$1058-4838 / 98 / 2601-0048 \$ 03.00$ isoniazid, rifampin, ethambutol, and pyrazinamide. The patient was in good health and afebrile. No cubital or axillary satellite adenopathies were found. A Mantoux test was positive (induration, $22 \mathrm{~mm}$ ) as a result of recent contact with a workmate who had tuberculosis, and findings on a chest radiograph were normal.

The technician was treated with $300 \mathrm{mg}$ of isoniazid and $600 \mathrm{mg}$ of rifampin daily for 6 months. The condition of his thumb improved slowly, and the pain progressively disappeared. No bone involvement was observed. After $>1$ year, the technician had recovered without sequelae from his needlestick accident.

Cutaneous tissue can be affected by tuberculosis in different ways [2]. Straight inoculation, as described in the present report, is rare. Infections due to close contact, such as fistulating tuberculous adenitis, are more frequent. Finally, hematogenous dissemination during the course of miliary tuberculosis can also give rise to skin lesions that usually present as papular forms showing central crusts [3].

Infection with tuberculosis by direct injection is rare. The skin is naturally resistant to tuberculosis; therefore, a breach of the cutaneous barrier is necessary to provoke infection [4]. This can occur following circumcision [5], tattooing [6], intramuscular injection [7], or mouthto-mouth resuscitation [8]. To our knowledge, only one case has been described where a syringe used on an HIV-positive patient with tuberculosis caused an accidental infection [9]. In that case, a nurse injured herself with the needle of a catheter removed from an HIVpositive patient with pulmonary tuberculosis.

The duration and the choice of treatment in cases of cutaneous tuberculosis cannot be based on data from large published series. Therapy has to be adapted on the basis of the local epidemiology of $M$. tuberculosis resistance patterns. The recommendations of the Medical Section of the American Lung Association for treatment of extrapulmonary tuberculosis are probably also valid for cutaneous infections caused by inoculation. The therapeutic regimen comprises triple therapy with isoniazid, rifampin, and pyrazinamide for 2 months, followed by dual therapy with isoniazid and rifampin for 4 months; thus, treatment is given for a total of 6 months [10].

Daniel Genné and Hans H. Siegrist

Department of Internal Medicine, Hospital, La Chaux-de-Fonds; and Neuchâtel Institute of Microbiology, La Chaux-de-Fonds, Switzerland

\section{References}

1. Pike RM. Laboratory-associated infections: incidence, fatalities, causes, and prevention. Annu Rev Microbiol 1979;33:41-66.

2. Beyt BE, Ortbals DW, Santa Cruz DJ, Kobayashi GS, Eisen AZ, Medoff G. Cutaneous mycobacteriosis: analysis of 34 cases with a new classification of the disease. Medicine (Baltimore) 1980;60:95-109.

3. Libraty DH, Byrd TF. Cutaneous miliary tuberculosis in the AIDS era: case report and review. Clin Infect Dis 1996;23:706-10. 
4. O'Leary PA, Harrison MW. Inoculation tuberculosis. Archives of Dermatology and Syphilology 1941;44:371-90.

5. Holt LE. Tuberculosis acquired through ritual circumcision. JAMA 1913; 61:99-102.

6. Dennie CC. Primary tuberculosis complex of the skin. Archives of Dermatology and Syphilology 1945;51:316-24.

7. Heycock JB, Noble TC. Four cases of syringe transmitted tuberculosis. Tubercle 1961;42:25-7.
8. Heilmann KM, Muschenheim C. Primary cutaneous tuberculosis resulting from mouth-to-mouth respiration. N Engl J Med 1965;273:1035-6.

9. Kramer F, Sasse SA, Simms JC, Leedom JM. Primary cutaneous tuberculosis after a needlestick injury from a patient with AIDS and undiagnosed tuberculosis. Ann Intern Med 1993; 119:594-5.

10. American Thoracic Society. Medical Section of the American Lung Association. Treatment of tuberculosis and tuberculosis infection in adults and children. Am Rev Dis 1986; 134:355-63.

\section{Successful Treatment of Primary Actinomyces viscosus Endocarditis with Third-Generation Cephalosporins}

Endocarditis due to Actinomyces species in the absence of any recognizable focus of infection elsewhere is extremely rare. Penicillin has been the standard treatment for this condition, but there are no clinical data on the use of alternative agents in cases where penicillin cannot be used. I describe a case of endocarditis due to Actinomyces viscosus in a penicillin-allergic patient who was treated successfully with third-generation cephalosporins.

An 81-year-old man with no history of valvular heart disease presented with depressed mood, suicidal ideation, anorexia, weight loss, and back pain. On physical examination he appeared pale, and his temperature was $38.5^{\circ} \mathrm{C}$, his pulse was $104 / \mathrm{min}$, and his blood pressure was 120/55 mm Hg. Funduscopic examination was unremarkable. Examination of his mouth revealed poor dental hygiene. Cardiac examination revealed a grade $1 / 6$ systolic murmur heard at the apex. Abdominal examination was negative for splenomegaly. Examination of the extremities did not reveal any petechiae, splinter hemorrhages, Osler's nodes, or Janeway lesions; clubbing was not observed. The remainder of the results of his physical examination were normal. Significant laboratory findings included the following values: WBC count, $11,300 / \mathrm{mm}^{3}$ (80\% polymorphonuclear leukocytes); hemoglobin, $10.5 \mathrm{~g} / \mathrm{dL}$; platelet count, $260,000 / \mathrm{mm}^{3}$; and erythrocyte sedimentation rate, $82 \mathrm{~mm} / \mathrm{h}$. Urinalysis revealed microscopic hematuria. Findings on an electrocardiogram were normal. A transthoracic two-dimensional echocardiogram demonstrated trace mitral regurgitation; no vegetations were detected. Two sets of blood cultures performed 1 day after admission yielded gram-positive bacilli after 4 days. These organisms, as well as isolates from two other sets of blood cultures performed 6 days after admission, were identified as $A$. viscosus by use of the API An-IDENT system (bioMérieux Vitek, Hazelwood, MO). The isolate produced catalase. MICs 48 hours after anaerobic incubation were as follows: penicillin

Reprints or correspondence: Dr. Kamal A. Hamed, Section of Infectious Diseases, Bay Pines Veterans Administration Medical Center 111J, 10,000 Veterans Boulevard, Bay Pines, Florida 33744.

Clinical Infectious Diseases 1998;26:211-2

This article is in the public domain.
$\mathrm{G}, \leqslant 0.06 \mu \mathrm{g} / \mathrm{mL} ;$ ampicillin/sulbactam, $\leqslant 0.5 \mu \mathrm{g} / \mathrm{mL}$; and cefotaxime, $\leqslant 0.5 \mu \mathrm{g} / \mathrm{mL}$.

The patient had a history of uvular edema and respiratory distress associated with penicillin treatment 30 years before this episode; therefore, therapy with iv ceftizoxime ( $2 \mathrm{~g} \mathrm{q} 8 \mathrm{~h}$ ) was started. Dental examination and radiographs showed caries but no acute dental infection. Four teeth were subsequently extracted. Subsequent physical examinations revealed an increase in the systolic murmur heard on admission (grade 1/6) to grade $3 / 6$ and a new decrescendo diastolic murmur grade $3 / 6$, best heard over the aortic area and left sternal border, with radiation to the carotid arteries. A repeated two-dimensional transthoracic echocardiogram and a transesophageal echocardiogram, performed 1 day apart, each demonstrated moderate mitral regurgitation, a thickened aortic valve with moderate aortic insufficiency, and a 1-cm highly mobile echogenic structure attached to the aortic valve, suggestive of a vegetation (figure 1). The patient was treated with iv ceftizoxime for 8 weeks and then with iv ceftriaxone (2 $\mathrm{g} \mathrm{q} 24 \mathrm{~h})$ as an outpatient for 4 weeks. Blood cultures performed several weeks after the end of antibiotic therapy were negative. The patient was doing well 1 year after the initial episode. There was no clinical evidence of congestive heart failure. His blood pressure remained in the range of $120 / 55 \mathrm{~mm} \mathrm{Hg}$, with no decrease in his pulse pressure.

Endocarditis caused by Actinomyces species is rare. Most cases are due to direct extension from the pericardium [1]. Only eight other cases of actinomycotic endocarditis, for which a portal of entry cannot be identified, have been reported since 1939 [2]. The clinical features of all nine cases (including this case) are similar to those of bacterial endocarditis due to other organisms.

Penicillin is the standard treatment for actinomycosis. For penicillin-allergic patients with other forms of actinomycosis, tetracycline, doxycycline, minocycline, erythromycin, clindamycin, cephalosporins, and chloramphenicol are suitable alternatives $[3,4]$. There is little clinical information available with respect to the newer antimicrobial agents, except for anecdotal success with ceftriaxone [5] and imipenem [6,7] for treatment of actinomycosis other than endocarditis. Although use of thirdgeneration cephalosporins in penicillin-allergic individuals appears to present only a slightly increased risk for drug reactions, these agents should be used with extreme caution, particularly in patients with a history of serious penicillin allergy.

This is the first case of actinomycotic endocarditis treated successfully with third-generation cephalosporins. The optimal dura- 

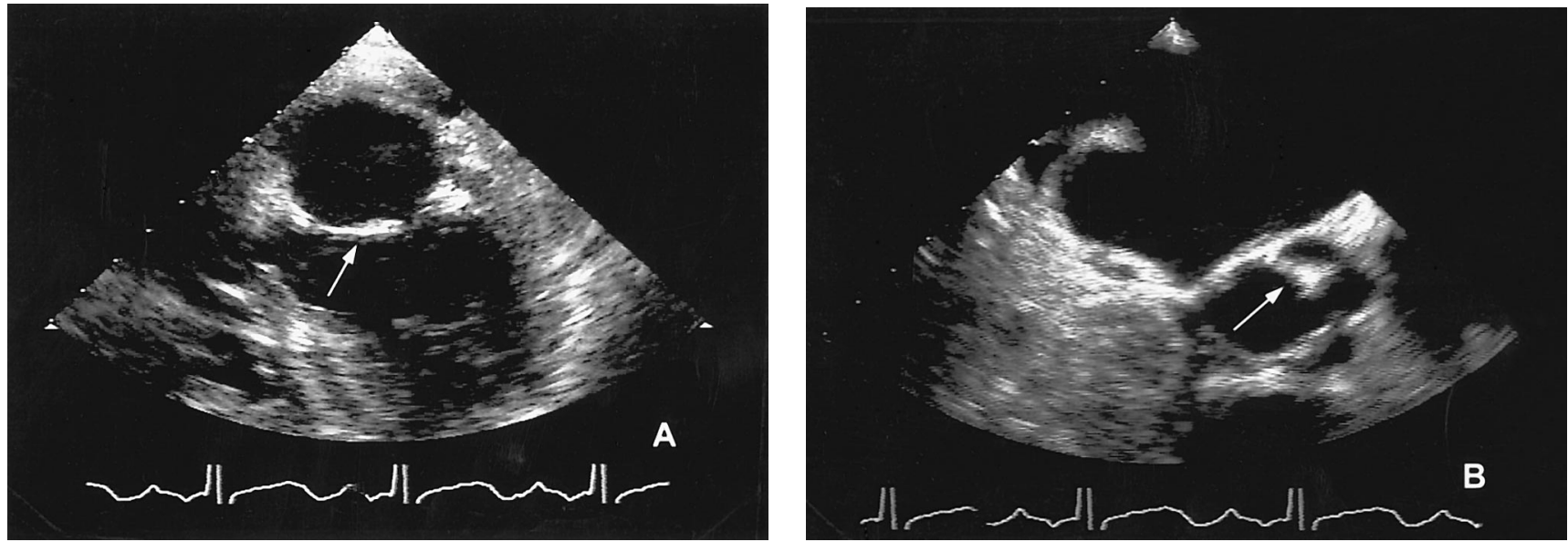

Figure 1. Transesophageal echocardiogram of a patient with aortic valve endocarditis due to Actinomyces viscosus. A, Aortic valve appears thickened (arrow); B, a freely mobile echogenic structure is attached to the aortic valve, consistent with a vegetation (arrow).

tion of therapy with this class of drugs and their clinical efficacy in the treatment of this condition merit further investigation.

\section{Kamal A. Hamed}

Section of Infectious Diseases, Medical Strategic Healthcare Group, Department of Veterans Affairs Medical Center, Bay Pines; and Department of Medicine, University of South Florida College of Medicine, Tampa, Florida

\section{References}

1. Dutton WP, Inclan AP. Cardiac actinomycosis. Dis Chest 1968;54:463-7.

2. Lam S, Samraj J, Rahman S, Hilton E. Primary actinomycotic endocarditis: case report and review. Clin Infect Dis 1993; 16:481-5.

\section{Polymerase Chain Reaction for the Diagnosis of Pleural Tuberculosis in Immunocompromised and Immunocompetent Patients}

Tuberculous pleural effusion (PE) usually occurs secondary to an immunologic reaction by the pleura to scant bacilli. The diagnosis of tuberculous PE is important because $60 \%-65 \%$ of patients with this condition will develop some other form of active tuberculosis [1].

Acid-fast staining and cultures have traditionally been used to identify Mycobacterium tuberculosis in pleural fluid (PF) for diag-

Reprints or correspondence: Dr. Victoria Villena, Servicio de Neumología, Hospital 12 de Octubre, Carretera de Andalucía Km 5.4, 28041 Madrid, Spain.

Clinical Infectious Diseases 1998;26:212-4

(C) 1998 by The University of Chicago. All rights reserved.

$1058-4838 / 98 / 2601-0049 \$ 03.00$
3. Russo TA. Agents of actinomycosis. In: Mandell GL, Bennett JE, Dolin R, eds. Mandell, Douglas and Bennett's principles and practice of infectious diseases. 4th ed. New York: Churchill Livingstone, 1995: $2280-88$.

4. Lerner PI. Susceptibility of pathogenic actinomycetes to antimicrobial compounds. Antimicrob Agents Chemother 1974; 5:302-9.

5. Skoutelis A, Petrochilos J, Bassaris H. Successful treatment of thoracic actinomycosis with ceftriaxone. Clin Infect Dis 1994; 19:161-2.

6. Edelmann M, Cullmann W, Nowak KH, Kozuschek W. Treatment of abdominothoracic actinomycosis with imipenem. Eur J Clin Microbiol 1987; 6:194-5.

7. Yew WW, Wong PC, Wong CF, Chau CH. Use of imipenem in the treatment of thoracic actinomycosis [letter]. Clin Infect Dis 1994; 19:983-4.

nosing pleural tuberculosis. Nevertheless, both methods have limitations. Staining is rapid, easy, and inexpensive but not very sensitive. The results of culture are not available for many weeks. However, PCR is a method that permits a quick diagnosis by the amplification of specific DNA sequences, including even a single copy of a given DNA sequence.

The aim of the present study was to evaluate the use of a PCR assay of PF for diagnosing pleural tuberculosis in the clinical setting.

We prospectively studied 131 patients (88 males; mean age, 56.7 years [range, 15-91 years]) with PE who had been examined in our service during the period January 1994 to December 1995. For a diagnosis of tuberculous PE, at least one of the following criteria had to be met: (A) a PF or tissue culture positive for M. tuberculosis; (B) the presence of necrotizing granulomas in a pleural biopsy specimen in the absence of other pleural granulomatous diseases; or (C) a clinical picture suggestive of pleural tuberculosis in association with a high IFN- $\gamma$ level in PF [2]. Only patients with scant PF, precluding pleural biopsy, who had favorable clinical courses after receiving antituberculous treatment were included in the third criterion. 
Table 1. Diagnostic methods used for patients with pleural tuberculosis.

\begin{tabular}{|c|c|c|c|c|c|c|}
\hline Patient no. & MCPF & МСРВ & Histology* & IFNG & $\mathrm{HIV}^{\dagger}$ & PCR \\
\hline 1 &,+- & + & + & 50 & $\mathrm{ND}$ & + \\
\hline 2 & + & - & + & 50 & - & + \\
\hline 3 & + & + & + & 50 & - & + \\
\hline 4 & + & - & - & 7 & + & + \\
\hline 5 & + &,-- &,-- & ND & ND & + \\
\hline 6 & + & + & - & ND & + & + \\
\hline 7 &,-- &,-+ &,-+ & 86 & - & - \\
\hline 8 & + & + & + & 81 & ND & + \\
\hline 9 &,,++- & + & + & 278 & - & - \\
\hline 10 &,,,--++ &,,--- &,,--+ & 1,700 & - & - \\
\hline 11 & - & + & + & 16 & - & - \\
\hline 12 &,-- & + & + & 27 & - & - \\
\hline 13 &,++ & - & + & 90 & - & + \\
\hline 14 &,-+ & - & + & 59 & $\mathrm{ND}$ & - \\
\hline 15 & + & ND & ND & 82 & $\mathrm{ND}$ & + \\
\hline 16 & + & + & + & 201 & $\mathrm{ND}$ & - \\
\hline 17 & + & ND & ND & 23 & - & + \\
\hline 18 & + & - & + & 46 & - & - \\
\hline 19 &,,-+- & ND & ND & 10 & $\mathrm{ND}$ & + \\
\hline 20 &,-- & + & + & 131 & $\mathrm{ND}$ & - \\
\hline 21 & - & - & + & 85 & - & + \\
\hline 22 &,,--- & - & + & 32 & - & - \\
\hline 23 & - & - & + & 74 & + & - \\
\hline 24 & - & - & + & 40 & - & - \\
\hline 25 &,-- & - & + & 53 & - & + \\
\hline 26 & - & - & + & 58 & - & - \\
\hline 27 & - & - & + & 56 & + & - \\
\hline 28 & - & - & + & 16 & - & - \\
\hline 29 & - & - & + & 199 & - & - \\
\hline 30 &,,--- & - & + & 19 & - & - \\
\hline 31 & - & - & + & 16 & + & - \\
\hline 32 & - & - & + & 56 & + & - \\
\hline 33 &,-- & ND & ND & 35 & + & + \\
\hline
\end{tabular}

NOTE. Multiple determinations are shown where performed; the first result is the sample in which PCR was performed. IFNG $=$ interferon $\gamma$ level in pleural fluid $(\mathrm{IU} / \mathrm{mL}) ; \mathrm{MCPB}=$ mycobacterial culture of pleural biopsy specimen; $\mathrm{MCPF}=$ mycobacterial culture of pleural fluid; $\mathrm{ND}=$ not done.

* Presence of granulomas in pleural biopsy specimen.

${ }^{\dagger}$ Serology for HIV.

An aliquot $(500 \mu \mathrm{L})$ of decontaminated and fluidified product was centrifuged at $9,500 \mathrm{~g}$ for 15 minutes. DNA was extracted by a simple lysis procedure with use of $50 \mu \mathrm{L}$ of lysis buffer containing $100 \mu \mathrm{g} / \mathrm{mL}$ of proteinase $\mathrm{K}[3,4]$. Five microliters of lysate in a 1:10 water dilution was used for the PCR assay to overcome the action of potential PCR inhibitors [3]. All reactions were carried out as described previously [3, 4], with minor modifications.

IFN- $\gamma$ was measured by immunoradiometric assay [2] of the PF obtained during the first thoracentesis. The statistical significance of differences in sensitivity was evaluated with the Fisher's exact test.

Thirty-three of the 131 patients met the criteria for tuberculosis, and 52 had neoplasms (13 with bronchogenic carcinomas; 11 with mesotheliomas; 3 each with breast and stomach carcinomas; 2 with ovarian carcinomas; 2 with non-Hodgkin's lymphoma; one each with colonic, adrenal, and vulvar carcinoma; and 15 with carcinomas of unknown origin); 16 had parapneumonic effusions; 13 had transudates; and 17 had other diagnoses ( 3 with uremic PE; 2 with pancreatitis; 2 with systemic lupus erythematosus; 2 with trapped lung; and 1 each with nontuberculous chylothorax, viral pleuropericarditis, pulmonary embolism, rheumatic polymyalgia, hemothorax, and postsurgery, posttraumatic, and postpartum PE).

The diagnostic methods used for each patient are shown in table 1. Acid-fast bacilli were not detected by auramine-rhodamine staining in any of the PF specimens.

The sensitivity $(95 \% \mathrm{CI})$ of PCR was $0.42(0.25-0.61)$, and the specificity was $0.99(0.94-1)$. With use of mycobacterial culture of PF obtained during the first thoracentesis, a diagnosis was made for $39 \%$ of the patients, and this percentage increased to $52 \%$ when both mycobacterial culture and PCR were performed. Histological study of the first pleural biopsy specimen showed granulomas for $83 \%$ of patients, and this percentage increased to $93 \%$ when PCR was also performed for more rapid diagnosis.

The sensitivity of PCR, in accordance with the diagnostic method used and HIV status, is shown in table 2. The 33 patients were classified in groups A (20 patients), B (12), or C (1), according to the diagnostic criteria for tuberculosis; if a patient had pleural granuloma and a culture of PF or tissue positive for M. tuberculosis, he or she was included in group A.

Only one patient with nontuberculous disease had a positive PCR result; she was a 70-year-old woman for whom PF cytology showed the presence of malignancy. Transbronchial biopsy performed during bronchoscopy revealed adenocarcinoma. However, a Mantoux test was positive, and she had had a lung nodule with calcifications detected when transbronchial biopsy was performed 4 years earlier.

Although PCR assay for the diagnosis of tuberculosis has been widely studied in recent years, its clinical value has not been fully determined. We agree with other authors [5-7] that PCR is more sensitive than culture of PF with use of Löwenstein-Jensen me-

Table 2. Sensitivity of PCR under different conditions for diagnosing pleural tuberculosis in 33 patients.

\begin{tabular}{|c|c|c|}
\hline Variable & $\begin{array}{l}\text { Sensitivity } \\
(95 \% \mathrm{CI})\end{array}$ & $P$ value* \\
\hline \multicolumn{3}{|c|}{$\begin{array}{l}\text { Mycobacterial culture of } \\
\text { pleural fluid (no. })^{\dagger}\end{array}$} \\
\hline Positive (13) & $0.77(0.46-0.95)$ & \multirow[t]{2}{*}{$<.005$} \\
\hline Negative (20) & $0.20(0.06-0.44)$ & \\
\hline \multicolumn{3}{|c|}{ Diagnostic group (no.) ${ }^{\ddagger}$} \\
\hline Group A (20) & $0.55(0.32-0.77)$ & \multirow[t]{2}{*}{$<.05$} \\
\hline Group B (12) & $0.17(0.02-0.48)$ & \\
\hline \multicolumn{3}{|c|}{ HIV serology (no.) } \\
\hline Negative (18) & $0.33(0.13-0.59)$ & \multirow[t]{2}{*}{ NS } \\
\hline Positive (7) & $0.43(0.10-0.82)$ & \\
\hline
\end{tabular}


dium. If both tests are performed, the diagnostic sensitivity increases; therefore, this combination may be useful if pleural biopsy is not feasible. In addition, in clinical practice the rapid diagnosis of tuberculosis is desirable, and pleural histology is usually the most useful test. The use of PCR increased the sensitivity of pleural biopsy, thus enabling determination of a diagnosis sooner in most cases.

In our study, PCR was found to be less sensitive than in other studies $[5,7]$. This finding could be inherent to the technique we used, but this technique was similar to the one used by Querol et al. [7]. It is more likely that our samples contained fewer bacilli. For instance, auramine-rhodamine staining, which is more sensitive than Ziehl-Neelsen staining [8], was not positive for any of our patients, and mycobacterial culture of either PF or pleural biopsy material was less sensitive in our study than in other studies [7]. However, the sensitivity of PCR for patients with negative mycobacterial cultures of PF was 0.2 in our study, similar to that in other studies $[5,6]$.

The sensitivity of PCR was greater for the samples of PF that were positive on mycobacterial culture than for those that were negative on mycobacterial culture and greater for the patients in group A rather than in group B, probably reflecting a larger number of bacilli in the PF specimens or tissues from these patients (table 2), as has been reported with other kinds of samples [3].

As far as we know, the sensitivity of PCR assay of PF from HIV-positive patients has not been studied. PCR has been reported as a useful test for the analysis of other fluids in this population [3]. In our series, the differences between HIV-positive and HIVnegative patients were not statistically significant.

\section{Rhabdomyolysis During the Subacute Stage of Meningococcal Sepsis}

Rhabdomyolysis secondary to fulminant meningococcal sepsis (FMS) has been reported in only one case report and one review article $[1,2]$. However, according to our experience, this complication may occur rather frequently.

From 1993 to 1996 we saw 34 patients with FMS in the intensive care unit (ICU) of the University Hospital Nijmegen, Nijmegen, the Netherlands. We observed the serum creatine phosphokinase (CPK) activity in 13 patients for $>30$ hours. Only two patients had normal CPK values, four patients had mild rhabdomyolysis (maximum CPK values, 785-1,219 U/L), and six patients developed severe rhabdomyolysis (maximum CPK values, $>5,000$ $\mathrm{U} / \mathrm{L}$ ) [3]. We discuss the cases of these latter six patients further.

Reprints or correspondence: Dr. Marcel van Deuren, Department of Internal Medicine, University Hospital Nijmegen, P.O. Box 9101, 6500 HB Nijmegen, the Netherlands.

Clinical Infectious Diseases $1998 ; 26: 214-5$

(C) 1998 by The University of Chicago. All rights reserved

$1058-4838 / 98 / 2601-0050 \$ 03.00$
Victoria Villena, $\mathbf{M}^{a}$. José Rebollo, Jose $\mathbf{M}^{a}$. Aguado, Antonia Galán, Angel López Encuentra, and Elia Palenque

Departments of Respiratory Medicine, Microbiology, and Infectious Diseases, Hospital Universitario 12 de Octubre, Madrid, Spain

References

1. Roper WH, Waring JJ. Primary serofibrinous pleural effusion in military personnel. Am Rev Respir Dis 1955;71:616-34.

2. Villena V, López Encuentra A, Echave-Sustaeta J, Martín Escribano P, Ortuño de Solo B, Estenoz Alfaro B. Interferon-gamma in 388 immunocompromised and immunocompetent patients for diagnosing pleural tuberculosis. Eur Respir J 1996;9:2635-9.

3. Folgueira L, Delgado R, Palenque E, Noriega AR. Detection of Mycobacterium tuberculosis DNA in clinical samples by using a simple lysis method and polymerase chain reaction. J Clin Microbiol 1993;31:1019-21.

4. Folgueira L, Delgado R, Palenque E, Noriega AR. Polymerase chain reaction for rapid diagnosis of tuberculous meningitis is AIDS patients. Neurology 1994; 44:1336-8.

5. De Wit D, Maartens G, Steyn L. A comparative study of the polymerase chain reaction and conventional procedures for the diagnosis of tuberculous pleural effusion. Tuber Lung Dis 1992; 73:262-7.

6. De Lassence A, Lecossier D, Pierre C, Cadranel J, Stern M, Hance AJ. Detection of mycobacterial DNA in pleural fluid from patients with tuberculous pleurisy by means of the polymerase chain reaction: comparison of two protocols. Thorax 1992;47:265-9.

7. Querol JM, Mínguez J, García Sánchez E, Farga MA, Gimeno C, García de Lomas J. Rapid diagnosis of pleural tuberculosis by polymerase chain reaction. Am J Respir Crit Care Med 1995; 152:1977-81.

8. Richeldi L, Barnini S, Saltini C. Molecular diagnosis of tuberculosis. Eur Respir J 1995; 8:689S-700S.

The predicted mortality for these six patients was $100 \%$ [4]. The median plasma concentration of TNF- $\alpha$ was $562 \mathrm{pg} / \mathrm{mL}$ (range, $165-720 \mathrm{pg} / \mathrm{mL}$; normal concentration, $94 \pm 22 \mathrm{pg} / \mathrm{mL}$ ); the median level of IL- $1 \beta$ was $120 \mathrm{pg} / \mathrm{mL}$ (range, $50-930 \mathrm{pg} / \mathrm{mL}$; normal level, $55 \pm 18 \mathrm{pg} / \mathrm{mL}$ ) [5]. In addition to anti-shock therapy, sodium bicarbonate, mannitol, or both were given to prevent myoglobinuria-induced renal failure. Five patients survived, and one patient died after 102 hours, when secondary renal failure had progressed.

The CPK values for these patients were normal on admission. After admission, however, the CPK values increased gradually to a median of 11,580 U/L (range, 7,314-33,100 U/L) at a median of 40 hours (range, 22.3-61.5 hours). Serum myoglobin levels increased to a median of 5,595 $\mu \mathrm{g} / \mathrm{L}$ (range, 3,720-7,680 $\mu \mathrm{g} / \mathrm{L}$ ), and urinary myoglobin levels increased to a median of 148,000 $\mu \mathrm{g} / \mathrm{L}$ (range, 26,900-154,800 $\mu \mathrm{g} / \mathrm{L}$ ).

The initial shock-related renal failure in these patients abated within 1-2 days. However, on day 4, renal failure progressed to anuria in the patient with the highest maximum $\mathrm{CPK}$ values. At autopsy, extensive deposits of myoglobin in distal and collecting tubules were seen (figure 1). Myoglobin was also observed in the cytoplasm and along the brush borders of proximal tubular cells.

Rhabdomyolysis secondary to bacterial infections may be caused by direct bacterial invasion, by cytokine-induced musclecell toxicity, or by muscle ischemia due to shock and diffuse 


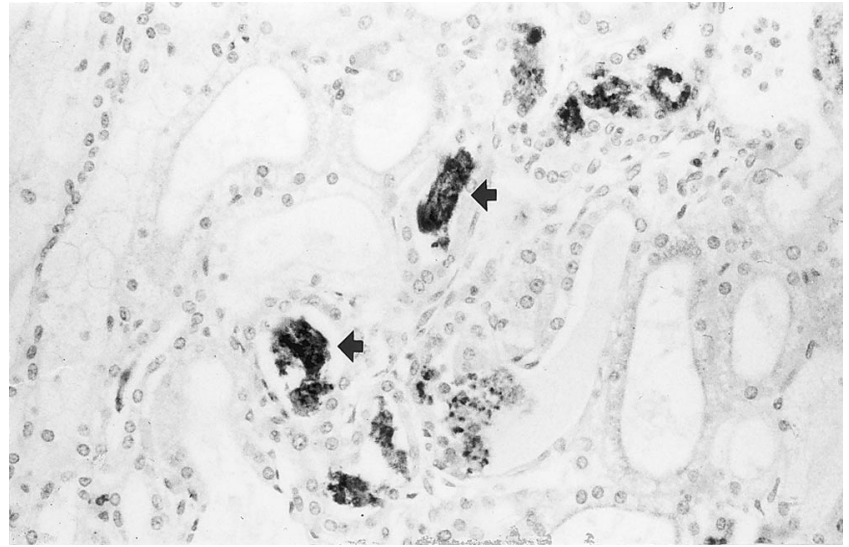

Figure 1. Myoglobin casts (arrows) in the distal tubular lumina of a renal autopsy specimen. The patient died with anuric renal failure. (Stain, indirect immunoperoxidase technique with use of rabbit antibody to human myoglobin; original magnification, $\times 300$.)

intravascular coagulation (DIC) [6,7]. FMS is characterized by high plasma concentrations of cytokines such as TNF- $\alpha$ and IL- $1 \beta$ [5]. These cytokines can elicit protein breakdown and membrane disturbances in muscle cells. In addition, they induce hypotension, endothelial damage, and DIC. In contrast to the other patients with FMS in our ICU during the study period, the patients described herein had extensive peripheral gangrene and high TNF- $\alpha$ and IL$1 \beta$ levels. These factors may all have contributed to muscle cell damage.

Most patients with FMS die within 1 day. Probably because of improved initial supportive care, which included plasma exchange or whole blood exchange [8], the patients described herein survived this acute phase. The evolving rhabdomyolysis during the following days required new attention because myoglobinuria may lead to renal failure. According to Ward [9], the probability that renal failure would occur in our patients was $>50 \%$. As management

\section{Progressive Multifocal Leukoencephalopathy in a Patient with Common Variable Immunodeficiency}

Progressive multifocal leukoencephalopathy (PML) is a rare demyelinating disease of the CNS, which results from the destruction of oligodendrocytes by the JC virus. PML is usually seen in patients with depression of cell-mediated immunity (e.g., those with HIV infection or hematologic malignancies as well as those who have undergone organ transplantation) $[1,2]$. We describe, to our knowledge, the first case of PML associated with common variable immunodeficiency.

Reprints or correspondence: Dr. P. G. Scotton, Divisione di Malattie Infettive, Ospedale Civile Cà Foncello, Piazza Ospedale, 31100, Treviso, Italy.

Clinical Infectious Diseases 1998;26:215-6

(C) 1998 by The University of Chicago. All rights reserved.

$1058-4838 / 98 / 2601-0051 \$ 03.00$ of fluid balance in the subacute stage of FMS is critical, the development of anuria during this stage poses a serious threat. Alkalinization and promotion of osmotic diuresis may prevent renal failure [10]. Thus, early recognition of this complication is warranted.

\section{Marcel van Deuren, Chris Neeleman, Karel J. M. Assmann, Jack F. M. Wetzels, and Jos W. M. van der Meer \\ Departments of General Internal Medicine, Intensive Care, Pathology, and Nephrology, University Hospital Nijmegen, Nijmegan, the Netherlands}

\section{References}

1. Chamberlain MC. Rhabdomyolysis in children: a 3-year retrospective study. Pediatr Neurol 1991; 7:226-8.

2. Brandtzaeg P. Systemic meningococcal disease: clinical pictures and pathophysiological background. Reviews in Medical Microbiology 1996; $7: 63-72$.

3. Veenstra J, Smit WM, Krediet RT, Arisz L. Relationship between elevated creatine phosphokinase and the clinical spectrum of rhabdomyolysis. Nephrol Dial Transplant 1994; 9:637-41.

4. Thomson APJ, Sills JA, Hart CA. Validation of the Glasgow meningococcal septicemia prognostic score: a 10-year retrospective survey. Crit Care Med 1991; 19:26-30.

5. Van Deuren M, Van der Ven-Jongekrijg J, Bartelink AKM, Van Dalen R, Sauerwein RW, Van der Meer JWM. Correlation between proinflammatory cytokines and antiinflammatory mediators and the severity of disease in meningococcal infections. J Infect Dis 1995; 172:433-9.

6. Gabow PA, Kaehny WD, Kelleher SP. The spectrum of rhabdomyolysis. Medicine (Baltimore) 1982;61:141-52.

7. Singh U, Scheld WM. Infectious etiologies of rhabdomyolysis: three case reports and review. Clin Infect Dis 1996;22:642-9.

8. Van Deuren M, Santman FW, Van Dalen R, Sauerwein RW, Span LFR, Van der Meer JWM. Plasma exchange and whole blood exchange in meningococcal sepsis. Clin Infect Dis 1992;15:424-30.

9. Ward MM. Factors predictive of acute renal failure in rhabdomyolysis. Arch Intern Med 1988; 148:1553-7.

10. Eneas JF, Schoenfeld PY, Humphreys MH. The effect of infusion of mannitol-sodium bicarbonate on the clinical course of myoglobinuria. Arch Intern Med 1979; 139:801-5.

A 38-year-old man was admitted to the neurology division of our hospital in September 1996 because of a 1-month history of diplopia. Neurological evaluation revealed right homonymous hemianopia and upward gaze palsy. A cerebral MRI revealed a non-ringenhancing confluent white-matter lesion in the left parieto-occipital lobe (figure 1); findings on a carotid arteriogram were normal. No further diagnostic procedures were performed. Two weeks after discharge, the patient was readmitted because of right hemiparesis and global aphasia. Cerebral positron emission tomography performed with ${ }^{18} \mathrm{~F}$ fluorodeoxyglucose revealed a site of decreased metabolism in the left temporoparietal-occipital region.

A stereotactic brain biopsy of the left parieto-occipital lesion was performed on 16 December 1996, and the diagnosis of PML was established. Histological examination revealed a zone of demyelination with giant astrocytes with pleomorphic and hyperchromatic nuclei and intranuclear inclusions in the oligodendrocytes; a few Toxoplasma cysts, without inflammatory cell infiltrates and necrosis, were seen; and in situ hybridization demonstrated the presence of JC virus. A PCR assay for JC virus in the CSF was 


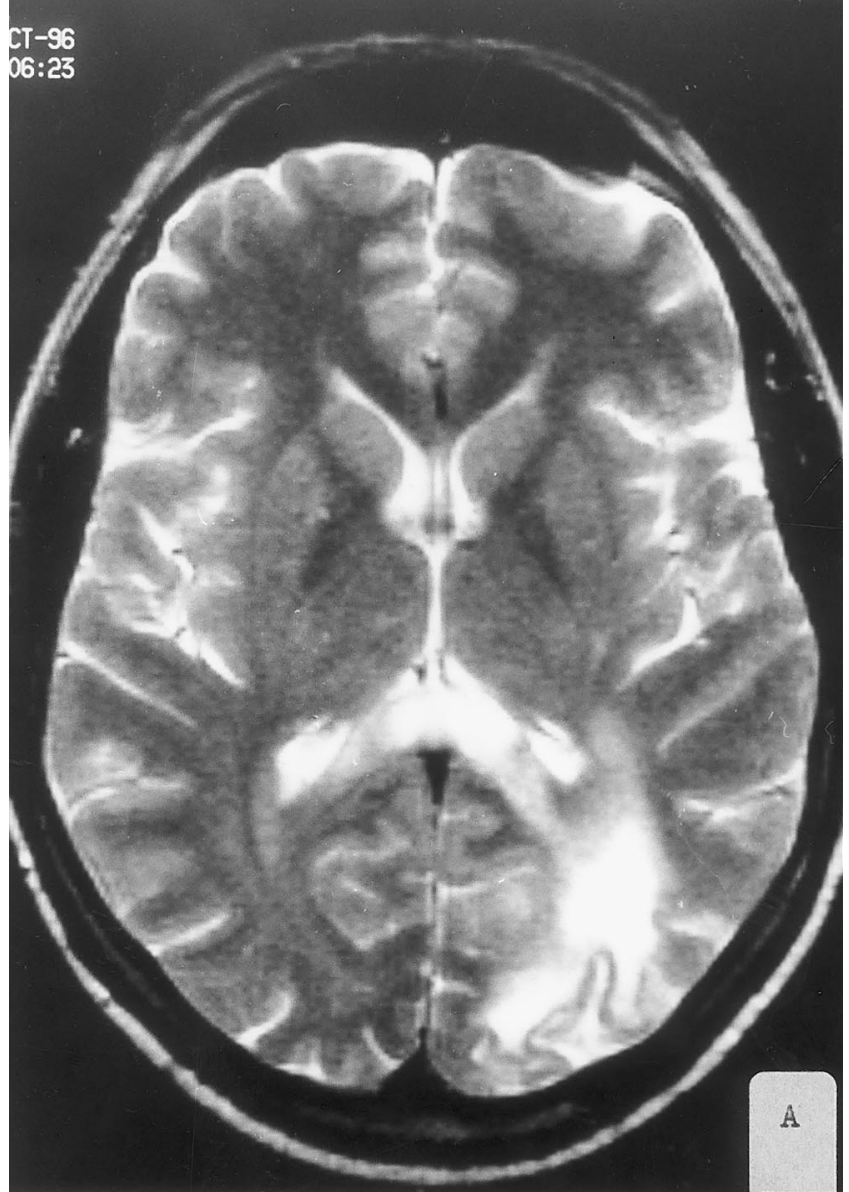

positive. An ELISA for antibodies to HIV and an assay for p24 antigen were negative; an assay for serum cytomegalovirus (CMV) antigen pp65 was positive at a low titer (4/200,000 polymorphonuclear neutrophils), as determined by immunofluorescence assay. Other laboratory studies revealed the following values: total blood lymphocyte count, 2,860/ $\mathrm{mm}^{3}$; B lymphocyte count, $290 / \mathrm{mm}^{3}$ (mean [ $\pm \mathrm{SD}$ ] normal count, $210 \pm 79 / \mathrm{mm}^{3}$ ); T lymphocyte count, $2,350 / \mathrm{mm}^{3}$ (mean $[ \pm \mathrm{SD}]$ normal count, $1,367 \pm 580 / \mathrm{mm}^{3}$ ); CD4 lymphocyte count, $1,540 / \mathrm{mm}^{3}$ (mean $[ \pm \mathrm{SD}$ ] normal count, $828 \pm$ $345 / \mathrm{mm}^{3}$ ); CD8 lymphocyte count, $1,030 / \mathrm{mm}^{3}$ (mean [ $\left.\pm \mathrm{SD}\right]$ normal count, $\left.669 \pm 284 / \mathrm{mm}^{3}\right) ; \mathrm{CD} 4 / \mathrm{CD} 8$ lymphocyte ratio, 1.5 (mean $[ \pm \mathrm{SD}]$ normal ratio, $1.6 \pm 0.4$ ); IgG level, $499 \mathrm{mg} / 100 \mathrm{~mL}$ (normal range, $800-1,800 \mathrm{mg} / \mathrm{dL}$ ); IgA level, $65 \mathrm{mg} / 100 \mathrm{~mL}$ (normal range, $90-450 \mathrm{mg} / \mathrm{dL}$ ); IgM level, $118 \mathrm{mg} / 100 \mathrm{~mL}$ (normal range, $60-280 \mathrm{mg} / \mathrm{dL}$ ); and $\mathrm{IgE}$ level, $13 \mathrm{U} / \mathrm{mL}$ (normal level, $<200 \mathrm{U} / \mathrm{L}$ ). Serum immunoelectrophoresis did not reveal the presence of paraprotein. Quantitative serum IgG subclasses (percentage of total $\mathrm{IgG}$ ), determined with use of the nephelometric method, were: IgG1, 83.5\% (range, 60.3\%-71.5\%); IgG2, $12.1 \%$ (range, 19.4\%-31.0\%); IgG3, 3.7\% (range, 5.0\%-8.4\%); and IgG4, $0.7 \%$ (range, $0.7 \%-4.2 \%$ ). Findings on examination of a bone-marrow aspirate were normal, and a thoracoabdominal CT did not show any abnormalities.

In most cases of PML reported previously, the patients have had a second disease associated with impairment of cell-mediated

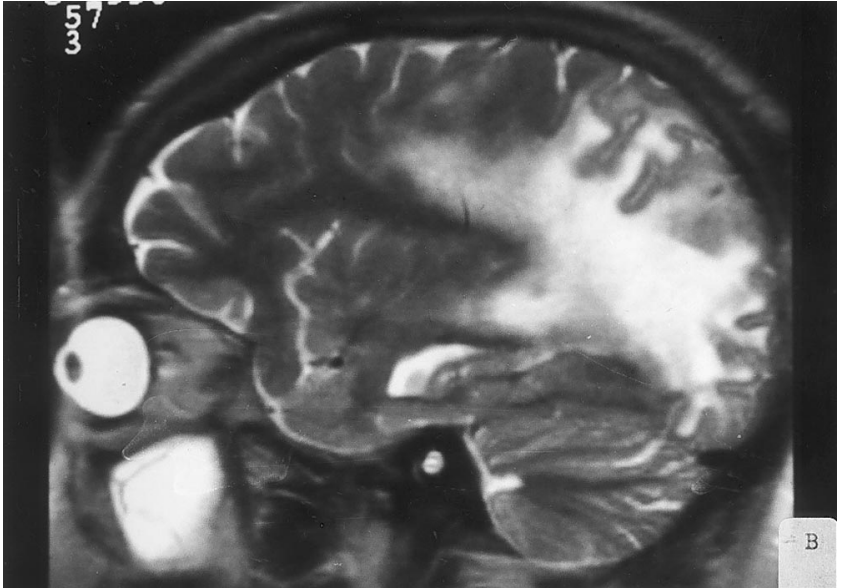

Figure 1. T2-weighted MRI shows a wide, confluent white-matter lesion in the left parieto-occipital lobe of a patient with progressive multifocal leukoencephalopathy and common variable immunodeficiency. $A$, transverse image; $B$, sagittal image.

immunity. The present case is unusual in that PML occurred in the presence of demonstrable humoral defects alone. In antibodydeficient patients, chronic encephalitis due to echovirus is a particular threat [3-5]; in addition, PML may be associated with this kind of immunodeficiency.

P. G. Scotton, A. Vaglia, A. Carniato, and G. C. Marchiori Departments of Infectious Diseases and Neurology, Cà Foncello Hospital, Treviso, Italy

\section{References}

1. Demeter LM. JC, BK, and other polyomaviruses; progressive multifocal leukoencephalopathy. In: Mandell, Douglas and Bennett's principles and practice of infectious diseases. 4th ed. Vol 2. New York: Churchill Livingstone, 1995:1400-6.

2. Major EO, Ault GS. Progressive multifocal leukoencephalopathy: clinical and laboratory observations on a viral induced demyelinating disease in the immunodeficient patient. Curr Opin Neurol 1995;8:184-90.

3. Sneller MC, Strober W, Eisenstein E, Jaffee JS, Cunningham-Rundles C. $\mathrm{NIH}$ conference. New insights into common variable immunodeficiency. Ann Intern Med 1993;118:720-30.

4. Spickett GP, Misbah SA, Chapel HM. Primary antibody deficiency in adults. Lancet 1991;337:281-4.

5. Rudge P, Webster AD, Revesz T, et al. Encephalomyelitis in primary hypogammaglobulinaemia. Brain 1996; 119:1-15. 


\section{Lepromatous Leprosy in a Renal Transplant Recipient}

In 1995, an estimated 1.8 million cases of leprosy occurred worldwide; most of them were concentrated in Southeast Asia, Africa, and the Americas [1]. With the exception of imported cases, leprosy is virtually absent in Canada, northern or western Europe, and the United States. There are $\sim 7,000$ patients with leprosy in the United States; these patients are mostly immigrants from Mexico, Southeast Asia, the Philippines, and the Caribbean. The annual incidence of newly diagnosed cases in the United States is 200 [2]. We used MEDLINE to search the English-language literature published from 1966 to the present for case reports of new-onset leprosy in organ-transplant recipients; however, we did not find any such reports. We report a case of lepromatous leprosy in a renal-transplant recipient.

A 25-year-old male who was born and lived in New Orleans underwent cadaveric kidney transplantation in 1987 because of acute tubular necrosis of unknown etiology. His HLA (human leukocyte antigen) phenotypes were A $(3,23), \mathrm{B}(7,-), \mathrm{C}(2,7)$, DR $(1,2)$, DQ $(1,-)$, and DRw $(-,-)$. After transplantation there were no episodes of rejection, opportunistic infection, or malignancy. He came to our attention in February 1997, when he developed multiple, nontender, nodular lesions that first appeared on his face and then spread to his neck, trunk, and extremities $\sim 2$ weeks before admission. He reported that, in retrospect, 6 months earlier he had noticed a few nontender bumps on his right cheek that had resolved with the application of antifungal cream. He also gave a history of progressive loss of hair, beard, eyelashes, and eyebrows over the past few weeks.

The patient's medical history was remarkable for hypertension and multiple blood transfusions that had been administered in 1986. He revealed that he had attended college in Baton Rouge, Louisiana, where he did gardening as part of the required curriculum. It is noteworthy that on many occasions, he had observed freeliving armadillos on the college grounds. He denied any history of travel or contact with leprous persons, and he had no pets. There was no family history of leprosy or similar skin disease. His immunosuppressive regimen included cyclosporine (225 mg q.d.) and prednisone (10 mg q.d.).

Physical examination did not reveal fever or palpable nerves, and findings of the neurological examination were normal. Examination of the skin disclosed multiple, waxy, nontender, nodular lesions on the face, neck, trunk, and extremities. Several scattered areas of alopecia and loss of beard, eyebrows, and eyelashes were also present. Laboratory studies revealed a leukocyte count of $20,700 / \mathrm{mm}^{3}$ with $92 \%$ polymorphonuclear neutrophils, a hemoglobin level of $7.7 \mathrm{~g} / \mathrm{dL}$, a creatinine level of $2.5 \mathrm{mg} / \mathrm{dL}$, an albumin level of $2.9 \mathrm{~g} / \mathrm{dL}$, a cyclosporine level of $121 \mathrm{ng} / \mathrm{mL}$, and trace proteinuria; findings on a chest radiograph were unremarkable. The patient declined HIV testing. A touch preparation of a skin

Reprints or correspondence: Dr. Pornthep Wattanamano, Infectious Diseases Section, SL-87, Tulane University School of Medicine, 1430 Tulane Avenue, New Orleans, Louisiana 70112.

Clinical Infectious Diseases $1998 ; 26: 217-8$

(C) 1998 by The University of Chicago. All rights reserved.

$1058-4838 / 98 / 2601-0052 \$ 03.00$ biopsy specimen from his neck revealed abundant acid-fast bacilli (AFB). Histopathologic examination revealed granulomatous inflammation and numerous vacuole-containing macrophages in the deeper dermis. A Fite stain was positive for abundant AFB in the macrophage vacuoles and in the dermis. Because the organisms did not grow in cultures of the skin biopsy specimen, the specimen was submitted to the Gillis W. Long Hansen's Disease Center in Carville, Louisiana, where a PCR assay for Mycobacterium leprae was performed; the assay was positive.

Smears of skin specimens from both earlobes and from skin folds at the elbows and knees demonstrated a bacteriologic index of $2+$ (at least one bacillus per high-power field) to $5+$ (at least 100 bacilli per high-power field) [3]. The patient was treated with a modified regimen for multibacillary disease, as recommended by the World Health Organization, consisting of dapsone (100 mg q.d.), clofazimine (50 mg q.d.), and rifampin (600 mg q.d.) [3]. The patient has been receiving therapy for 3 months and has not had any disease reaction or extension. His eyebrows have started to grow back, and the skin nodules have diminished in size.

We thought this case was interesting for several reasons. First, it represents the first report of new-onset leprosy in a transplant recipient. There is one previous report of the relapse of leprosy following renal transplantation [4]. In view of the vulnerability of transplant patients to mycobacterial infection, the rarity of leprosy in this population may result from the relative infrequency of organ transplantation in areas where M. leprae is endemic. In the future, infection with $M$. leprae may become more common in transplant recipients if organ transplantation becomes available in less developed countries.

Second, there is the question of how the patient acquired this infection and why he developed the lepromatous form. M. lepraespecific phenoglycolic acid (PGL-1) has been found in soil in the vicinity of armadillos [5]. Since the patient had no direct contact with armadillos, we postulate that he may have been exposed to M. leprae while working with soil in Baton Rouge, an area where armadillos are indigenous [6]. The reason for the lepromatous manifestation of our patient's disease is probably complex, involving an interplay between cell-mediated immunosuppression (via interference by cyclosporine and prednisone with the TH1 and IL-2 immune responses) and a genetic predisposition [7,8]. It is noteworthy that this patient possesses HLA-DR2 and HLA-DQ1 alleles, both of which are strongly associated with lepromatous leprosy [8].

Finally, this case illustrates the importance of including leprosy in the differential diagnosis of unusual skin lesions in immunocompromised hosts. On the basis of the acid-fast smear results, we initially suspected a disseminated infection due to a rapidly growing mycobacterium, and we treated the patient accordingly. However, the fact that AFB from an AFB-smear-positive specimen did not grow in culture, as well as the characteristic histopathology, were clues to the proper diagnosis.

David M. Mushatt, Pornthep Wattanamano, and Fernando S. Alvarado

Infectious Diseases Section, Department of Medicine, Tulane University School of Medicine, New Orleans, Louisiana

References

1. World Health Organization. A Guide to eliminating leprosy as a public health problem. Lepr Rev 1996;67:151-61. 
2. Gelber RH. Leprosy (Hansen's disease). In: Mandell GL, Bennett JE, Dolin R, eds. Mandell, Douglas and Bennett's principles and practice of infectious diseases. 4th ed. Vol 2. New York: Churchill Livingston, 1996:2243-50.

3. Yoder. Hansen's Disease. A guide to management in the United States. Internal publication. Carville, Louisiana: Hansen's Disease Center, and U.S. Public Health Service, 1995.

4. Teruel JL, Liano F, del Hoyo M, et al. Successful kidney transplantation in leprosy and transitory recurrence of the disease. Int J Lepr 1985; 53: 410-1.

\section{Regression of Invasive AIDS-Related Kaposi's Sarcoma Following Antiretroviral Therapy}

Kaposi's sarcoma (KS) is the most common neoplasm in patients with AIDS [1]. The KS-associated herpesvirus (KSHV) and the HIV-1 regulatory gene tat have been involved in the pathogenesis of $\operatorname{KS}[2,3]$.

The enhanced immune response achieved with combined antiretroviral therapies has been shown to induce remission of certain AIDS-related events. We report, to our knowledge, the first case of regression of invasive KS in a patient with AIDS who received aggressive antiretroviral therapy.

A 44-year-old heterosexual man who was infected with HIV-1 was admitted to the hospital before starting antiretroviral treatment because of probable Pneumocystis carinii pneumonia.

The patient had nodular and violaceous lesions on the face, chest, left palate, knee, and right arm. These lesions ranged from $0.5 \mathrm{~cm}$ to $3 \mathrm{~cm}$ in size and were confirmed to be $\mathrm{KS}$ by histopathologic examination. Multiple and painful inguinal lymphadenopathies were also found, but they were not biopsied. A chest radiograph demonstrated a bilateral interstitial infiltrate. The $\mathrm{CD}^{+}{ }^{+}$and $\mathrm{CD} 8^{+}$lymphocyte counts were $124 \times 10^{6} / \mathrm{L}$ and $1,609 \times 10^{6} / \mathrm{L}$, respectively.

Fiberoptic bronchoscopy was performed because the patient's condition did not improve despite treatment with trimethoprimsulfamethoxazole. Two raised and violaceous endobronchial tumors in the segmental apical and the lobar left bronchi, suggestive of KS, were visualized on bronchoscopy. Histopathologic examination of an endoscopic biopsy specimen from one of the endobronchial lesions disclosed the typical features of KS.

This patient's KS was classified as stage IV [4]. Treatment with zidovudine (250 mg b.i.d.), didanosine (200 mg b.i.d.), stavudine (40 mg b.i.d.), and the HIV-1 protease inhibitor saquinavir (600 mg t.i.d.) was started. Twelve weeks later, therapy with didanosine was changed to that with lamivudine ( $150 \mathrm{mg}$ b.i.d.) because acute gout developed. The mucocutaneous lesions regressed 20 weeks after the antiretroviral therapy was started. The endobronchial tumors disappeared, as confirmed by examination of multiple biopsy specimens

Reprints or correspondence: Dr. Manuel Leal, Department of Internal Medicine, Viral Hepatitis and AIDS Study Group, Virgen del Rocío University Hospital, Avenida Manuel Siurot s/n, 41013-Seville, Spain. E-mail: mleal@, cica.es

Clinical Infectious Diseases 1998;26:218-9

(C) 1998 by The University of Chicago. All rights reserved.

$1058-4838 / 98 / 2601-0053 \$ 03.00$
5. Blake LA, West BC, Lary CH, et al. Environmental nonhuman sources of leprosy. Rev Infect Dis 1987;9:562-77.

6. Lumpkin LR, Cox GF, Wolf JE, et al. Leprosy in five armadillo handlers. J Am Acad Derm 1983;9:899-903

7. Modlin RL, Bloom BR. Immune regulation: learning from leprosy. Hosp Pract 1993;28 (11):71-84.

8. Singh N, Agrawal S, Rastogi AK. Infectious diseases and immunity: special reference to major histocompatibility complex. Emerg Infect Dis 1997; $3: 41-9$.

obtained 1 month later during repeated bronchoscopy. No inguinal lymphadenopathies were found on repeated examinations. All of the patient's KS lesions remain in remission 5 months later.

Quantification of HIV-1 RNA and detection of KSHV were done as previously described $[2,5]$. Eight weeks before the treatment was started, human herpesvirus (HHV)-8 DNA sequences were not detected. Nevertheless, 8 weeks after treatment was begun, HHV-8 DNA sequences were detectable. The serum HIV-1 viral load was 28,150 copies/mL when the therapy was started. The viral load remained $<500$ copies $/ \mathrm{mL}$ from the fourth to the 20th week of therapy. The evolution of the $\mathrm{CD} 4^{+}$cell count is shown in figure 1 .

The use of systemic chemotherapy is limited in patients with AIDS-related KS and advanced immunodeficiency because of the adverse effects [6]. Regression of cutaneous AIDS-related KS following antiretroviral therapy has been reported previously [7]. However, the present report represents the first case of regression of invasive KS following antiretroviral therapy.

A marked decrease in the HIV-1 viral load and an increase in the $\mathrm{CD}^{+}$cell count preceded the resolution of our patient's grade IV KS. This regression could be explained by several hypotheses. First, antiretroviral drugs could have a direct effect on the clearing of the HHV-8 infection. However, in the present case, the HHV8 DNA was detected 8 weeks after treatment was started. This finding could be due to a large repopulation of immune cells, including B lymphocytes, that harbored HHV-8. Second, use of a potent antiretroviral drug combination can result in dramatic

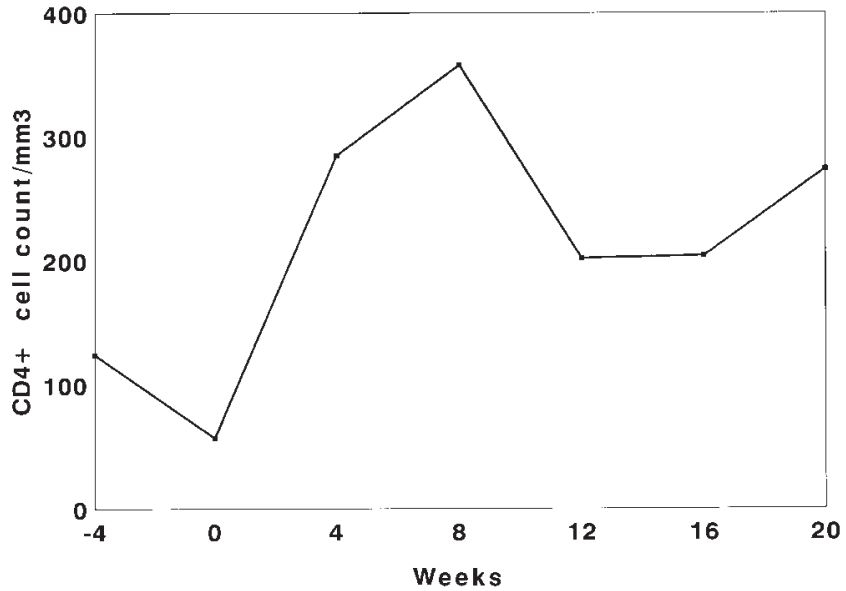

Figure 1. Evolution of the $\mathrm{CD} 4^{+}$cell count in a patient with AIDSrelated Kaposi's sarcoma following antiretroviral therapy. 
decreases in HIV-1 replication that would reduce the level of tat gene expression, and this reduced level of expression could induce neither angiogenesis nor malignant transformation of endothelial cells by tat-induced cytokines [3]. Third, the use of antiretroviral agents could be associated with an improvement in the immune response, enabling control of tumor progression.

Further studies are needed to better determine the therapeutic effects of antiretroviral therapy on the progression of KS in HIVinfected patients. Combinations of these drugs could become alternatives to the conventional treatment of AIDS-related KS.

Ricardo Parra, Manuel Leal, Juan Delgado, Juan Macías, Amalia Rubio, Fernando Gómez, Vicente Soriano, Armando Sanchez-Quijano, Juan Antonio Pineda, and Eduardo Lissen

Viral Hepatitis and AIDS Study Group, Virgen del Rocío University Hospital, Seville; and Service of Infectious Diseases, Instituto de Salud Carlos III, Madrid, Spain
References

1. Beral V. Epidemiology of Kaposi's sarcoma. Cancer Surveys 1991;10: $5-22$.

2. Chang Y, Cesarman E, Pessin M, et al. Identification of herpes virus-like DNA sequences in AIDS-associated Kaposi's sarcoma. Science 1994; 266:1865-9.

3. Barillari G, Buonaguro L, Fiorelli V, et al. Effects of cytokines from activated immune cells on vascular cell growth and HIV-1 gene expression. J Immunol 1992; 149:3727-34.

4. Krown SE, Metroka C, Wernz JC, et al. Kaposi's sarcoma in acquired immunodeficiency syndrome: a proposal for a uniform evaluation, response and stating criteria. J Clin Oncol 1989;7:1201.

5. Kern D, Collins M, Fultz T, et al. An enhanced-sensitivity branched-DNA assay for quantification of human immunodeficiency virus type 1 RNA in plasma. J Clin Microbiol 1996;34:3196-202.

6. Mitsuyasu RT. Clinical aspects of AIDS-related Kaposi's sarcoma. Curr Opin Oncol 1993; 5:835-44.

7. Langford A, Ruf B, Kunze R, Pohle H-D, Reichart P. Regression of oral Kaposi's sarcoma in a case of AIDS on zidovudine (AZT). Br J Dermatol $1989 ; 120: 709-13$.

\section{Three Episodes of Tuberculosis - To Multidrug Resistance and Back to Susceptibility}

We report the case of a patient who had three episodes of tuberculosis; two of these episodes were due to resistant strains of Mycobacterium tuberculosis, and one was due to a susceptible strain.

A 31-year-old Tibetan woman who was born in India developed smear-positive tuberculosis (TB) of the lung in 1987, 1990, and 1995. Upon immigration to Switzerland in 1984, findings on her chest radiograph were normal. Three years later, progressive, cavernous TB of the left upper lobe was diagnosed (episode 1). M. tuberculosis was isolated from sputum and gastric fluid specimens, and primary resistance to isoniazid was detected. The patient was hospitalized and treated with isoniazid, rifampin, and pyrazinamide for 2 months, followed by a regimen of rifampin and ethambutol for 4 months. After 14 weeks of treatment, cultures became negative.

After the patient recovered clinically, she traveled to India and Nepal in 1989; however, upon her return in 1990, she developed a cough and night sweats, and cavernous TB of the left upper lobe, with laryngeal and endobronchial involvement, was diagnosed (episode 2). The $M$. tuberculosis isolate proved to be resistant to

Reprints or correspondence: Dr. Gaby E. Pfyffer, Swiss National Center for Mycobacteria, Department of Medical Microbiology, University of Zurich, Gloriastrasse 30, 8028 Zurich, Switzerland.

Clinical Infectious Diseases 1998;26:219-20

(C) 1998 by The University of Chicago. All rights reserved. $1058-4838 / 98 / 2601-0054 \$ 03.00$ isoniazid, rifampin, and streptomycin. Treatment with isoniazid, rifampin, ethambutol, pyrazinamide, and ciprofloxacin was started; therapy with the latter three drugs was continued for 12 months. After she recovered, she traveled several times to India between 1990 and 1993 and subsequently worked as an assistant nurse at the University Hospital in Zurich. In the fall of 1995, she complained of pain under the right scapula and developed a productive cough, malaise, fever, and night sweats. An infiltrate was observed on a chest radiograph, and pulmonary TB with right-sided cervical lymphadenitis was diagnosed (episode 3 ). For the third time, cultures were positive, but surprisingly, the M. tuberculosis isolate was fully susceptible to all first-line drugs.

This finding prompted us to study all isolates at the molecular level to better understand this case. By using $P v u \mathrm{II}$ as the restriction enzyme and IS6110 as a probe [1], we found two different patterns of restriction fragment length polymorphism (RFLP): the isolates recovered during episode 1 and episode 2 had identical DNA fingerprints, whereas those recovered during episode 3 differed considerably from the initial strains. On probing $A l u \mathrm{I}$-digested DNA with the polymorphic GC-rich repetitive sequence [2], banding patterns for the isolates from episodes 1 and 2 were again found to differ from those of episode 3.

On the basis of this case, three major conclusions can be drawn: (1) Of the two episodes of TB in 1990 and 1995, only one was a true relapse, probably caused by inadequate drug therapy. Conversely, episode 3 was due to exogenous reinfection. (2) Treatment of TB after episode 2 was successful, as indicated by the significant improvement in the patient's condition and the numerous culturenegative follow-up specimens that were obtained. (3) A mixedstrain infection during episode 3 can be safely ruled out, not only on account of the DNA fingerprinting results but also because of the isolate's susceptibility pattern (fully susceptible), which 
excludes the presence of the previous strains (resistant to isoniazid and to multiple drugs).

Since the strain recovered from the patient's sister, who had active TB in 1984, was not available for typing, it is not clear whether the patient became infected via her sister or whether she was infected while living in Tibet. The latter scenario is quite likely, since the incidence of TB among Tibetan immigrants living in Switzerland is very high (384 cases per 100,000 persons; P. Helbling, Swiss Federal Office of Public Health, personal communication). In addition, the time of reinfection with the fully susceptible strain is not known.

Exogenous reinfection has been demonstrated conclusively in patients with advanced HIV infection [3], but such reinfection has also been reported among immunocompetent individuals with either alcoholism [4] or diabetes [5] as risk factors. The patient described herein had neither underlying disease nor other known risk factors. To our knowledge, this is the first well-documented case demonstrating that both relapse of $\mathrm{TB}$, with progression to multidrug-resistant $\mathrm{TB}$, followed by exogenous reinfection and development of active disease within a short period ( 8 years) is possible within the same patient. A history of frequent travel to areas where TB is highly prevalent supports the assumption that in such countries, exogenous reinfection may be a common mechanism by which clinical TB develops [6]. If so, global strategies

\section{Inflammatory Tinea Corporis Due to Trichophyton verrucosum}

A recent report by Sabota et al. describes tinea barbae due to Trichophyton verrucosum in dairy farmers [1]. T. verrucosum may also cause other infections including tinea corporis [2,3], and other animals, such as horses, may be the source of infection $[4,5]$. We describe a patient, with horse contact, who developed inflammatory tinea corporis due to T. verrucosum, confirmed by histopathology and culture results.

A 54-year-old man, whose work involved riding horses in rural areas, presented with left leg tenderness and erythema; he had no fever or other systemic symptoms. There was no response to treatment with oral flucloxacillin and roxithromycin. A biopsy of the leg lesion was performed. A gram stain of the specimen was negative, but coagulasenegative staphylococci were isolated, and histopathology demonstrated nonspecific chronic inflammatory changes with folliculitis. Treatment with flucloxacillin ( $1 \mathrm{~g} \mathrm{q6h}$ iv) and oral ciprofloxacin (750 $\mathrm{mg}$ b.i.d.) was begun, but there was no improvement in the patient's condition.

Seven weeks after his initial presentation, he was referred to our institution for consideration of hyperbaric oxygen therapy for "cellulitis" that was not responding to therapy with antibacterial agents. Examination of the medial aspect of the left leg revealed a $15 \times 6-\mathrm{cm}$, erythematous, indurated plaque, containing pustular lesions with ne-

Reprints or correspondence: Dr. Tony Korman, Department of Microbiology, Monash University, Clayton Victoria 3168 Australia.

Clinical Infectious Diseases 1998;26:220-1

(C) 1998 by The University of Chicago. All rights reserved.

$1058-4838 / 98 / 2601-0055 \$ 03.00$ for TB control must be aimed primarily at minimizing transmission, i.e., eliminating M. tuberculosis in such environments.

Gaby E. Pfyffer, Anni Strässle, Otto Brändli, and Helena Shang

Swiss National Center for Mycobacteria, Department of Medical Microbiology, University of Zurich, Zurich; and Zürcher Höhenklinik Wald, Faltigberg, Switzerland

\section{References}

1. Van Embden JDA, Cave MD, Crawford JT, et al. Strain identification of Mycobacterium tuberculosis by DNA fingerprinting: recommendations for standardized methodology. J Clin Microbiol 1993;31:406-9.

2. Poulet S, Cole ST. Repeated DNA sequences in mycobacteria. Arch Microbiol 1995; 163:79-86.

3. Small PM, Shafer RW, Hopewell PC, et al. Exogenous reinfection with multi-drug resistant Mycobacterium tuberculosis with advanced HIV infection. N Engl J Med 1993;328:1137-44.

4. Shafer RW, Singh SP, Larkin C, Small PM. Exogenous reinfection with multi-drug resistant Mycobacterium tuberculosis in an immunocompetent patient. Tuber Lung Dis 1995; 76:575-7.

5. Turett GS, Fazal BA, Justman JE, Alland D, Duncalf RM, Telzak EE. Exogenous reinfection with multidrug-resistant Mycobacterium tuberculosis. Clin Infect Dis 1997;24:513-4.

6. Styblo K. Epidemiology of tuberculosis. Bull Int Union Tuberc 1978; 53: $141-52$.

crotic areas (figure 1). There was no fever or inguinal lymphadenopathy. Results of a complete blood count and blood chemistry evaluation were normal, and the erythrocyte sedimentation rate was $13 \mathrm{~mm} / \mathrm{h}$. Repeated skin biopsy was performed, and results of gram and acidfast stains as well as routine bacterial and mycobacterial cultures were negative. Histopathologic evaluation demonstrated a mixed inflammatory cell infiltrate and a fungal spore (figure 1). After 2 weeks' incubation at $30^{\circ} \mathrm{C}, T$. verrucosum was isolated. Oral itraconazole $(200 \mathrm{mg}$ b.i.d.) was administered for 12 weeks, and the leg lesion resolved completely.

Chronic tinea corporis is uncommon and is usually due to either Trichophyton mentagrophytes or T. verrucosum [4]. T. verrucosum is distributed globally [5], and human infection has been reported previously from Australasia $[6,7]$. T. verrucosum usually infects cows, but it is also isolated frequently from horses [4]. In the current case, the lesion was on the patient's leg, where there had been direct contact with a common site of horse ringworm [4]. Zoophilic dermatophytes like $T$. verrucosum may produce inflammatory disease that can be mistaken for bacterial infection $[1,5,8]$. Tinea corporis due to zoophilic dermatophytes may resolve spontaneously, but systemic antifungal therapy is usually required $[5,9]$.

In cases of tinea corporis, biopsies may demonstrate cylindrical fungal filaments, or rounded arthroconidia [10], which are characteristically large in $T$. verrucosum infection [3]. In inflammatory tinea corporis caused by zoophilic dermatophytes such as $T$. verrucosum, hypersensitivity reactions may produce vesicles and papules accompanied by dermal infiltrates [10], or vasculitis characterized by small follicular papules with necrotic areas [3]. Histopathologic features of hypersensitivity reactions include infiltration of lymphocytes, plasma cells, neutrophils, and eosinophils into the dermis [10].

Tinea corporis due to $T$. verrucosum should be included in the differential diagnosis of chronic inflammatory skin lesions in patients with a history of contact with animals, including cows and horses. 

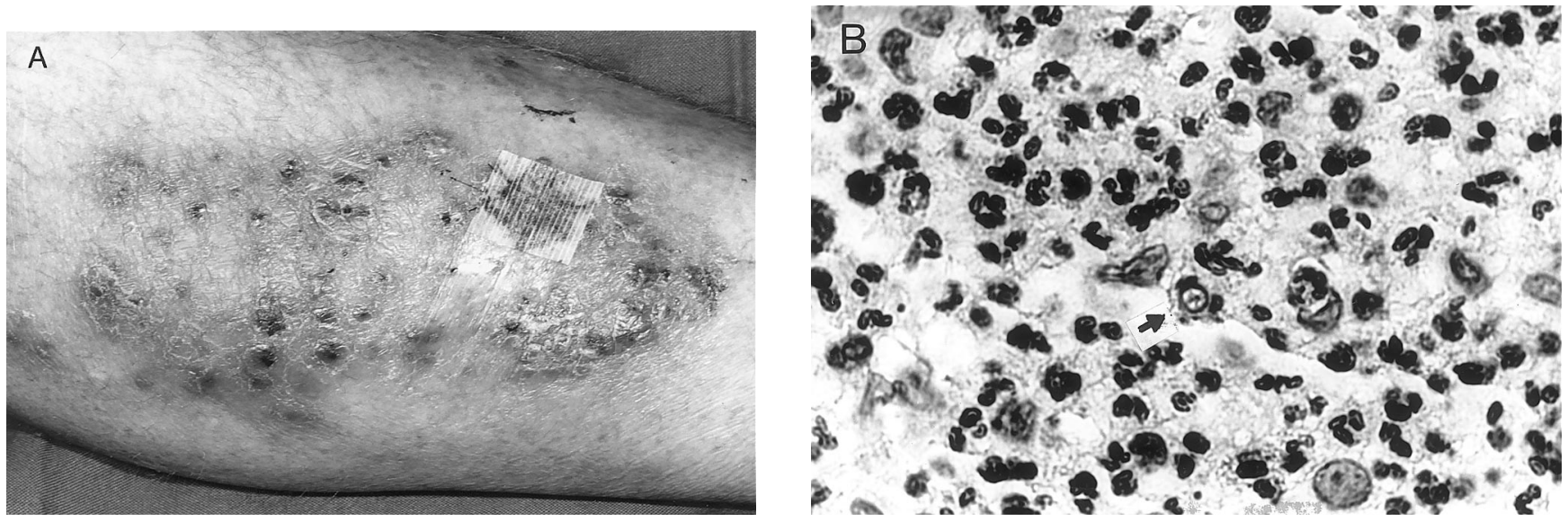

Figure 1. $A$ : An erythematous, indurated plaque $(15 \times 6 \mathrm{~cm})$, containing pustular lesions with necrotic areas on the medial aspect of the left leg of a patient with infection due to Trichophyton verrucosum. B: Photomicrograph of biopsy specimen from a skin lesion on the patient. A mixed inflammatory cell infiltrate in the dermis surrounds a fungal spore (arrow) that measures $10 \times 12 \mu \mathrm{m}$. (Periodic acid-Schiff stain; original magnification, $\times 1,000$.)

\section{Acknowledgment}

The authors thank Alan Woodgyer from the Microbiological Diagnostic Unit, University of Melbourne, for confirming the identification of the T. verrucosum isolate.

Tony M. Korman, Andrew Fuller, and John P. Dowling Department of Microbiology and Infectious Disease and Department of Pathology, Alfred Hospital, Inner and Eastern Health Care Network, Prahran, Victoria, Australia

\section{References}

1. Sabota J, Brodell R, Rutecki GW, Hoppes WL. Severe tinea barbae due to Trichophyton verrucosum infection in dairy farmers. Clin Infect Dis 1996; $23: 1308-10$.

2. Weksberg F, Fisher BK. Unusual tinea corporis caused by Trichophyton verrucosum. Int J Dermatol 1986;25:653-5.

\section{Primary Psoas Muscle Abscess Due to Mycobacterium xenopi}

Mycobacterium xenopi is a well-documented cause of nontuberculous mycobacterial pulmonary disease, particularly in western Europe [1]. However, reports of extrapulmonary infections remain rare [2]. We present an unusual case of primary psoas muscle abscess caused by $M$. xenopi.

A 65-year-old man presented with a 3-week history of persistent left flank pain and weight loss. His medical history included anthra-

Reprints or correspondence: Dr. Th. Prigogine, CHU Brugmann, Place A. Van Gehuchten 4-1020, Brussels, Belgium.

Clinical Infectious Diseases 1998;26:221-2

(C) 1998 by The University of Chicago. All rights reserved.

$1058-4838 / 98 / 2601-0056 \$ 03.00$
3. Hay RJ. Dermatophytosis and other superficial mycoses. In: Mandell GL, Bennett JE, Dolin R, eds. Mandell, Douglas and Bennett's principles and practice of infectious diseases. 4th ed. New York: Churchill Livingstone, 1995:2375-86.

4. Rippon JW. Dermatophytes and dermatophytosis. In: Medical mycology: the pathogenic fungi and pathogenic actinomycetes. 3rd ed. Philadelphia: W.B Saunders, 1988:169-275.

5. Kwon-Chung KJ, Bennett JE. Dermatophytosis. In: Medical mycology. Philadelphia: Lea \& Febiger, 1992:105-61.

6. Hunter GA, Sheppard RA. A case of human ringworm due to Trichophyton verrucosum in South Australia. Australas J Dermatol 1966;8:232-3.

7. Scrimgeour G, Langford T, Coutts R. A deep seated Trichophyton verrucosum infection. Mycoses Newsletter 1994;4:25-6.

8. Radentz WH. Fungal skin infections associated with animal contact. Am Fam Physician 1991; 43:1253-6.

9. Halasz CL. Successful treatment with fluconazole of tinea corporis caused by Trichophyton verrucosum (barn itch). Cutis 1994;54:207-8.

10. Weitzman I, Summerbell RJ. The dermatophytes. Clin Microbiol Rev $1995 ; 8: 240-59$.

cosilicosis, which had been diagnosed years before. Four months before presentation, he had undergone coronary angiography and angioplasty for ischemic coronary disease.

On examination, the patient was afebrile; he had tenderness in the left flank but no pain on motion of either the hip or the spine. A chest radiograph disclosed diffuse reticulonodular infiltrates. The WBC count was within normal limits, but the erythrocyte sedimentation rate (ESR) was $52 \mathrm{~mm} / \mathrm{h}$, and the C-reactive protein level was $8.9 \mathrm{mg} / \mathrm{dL}$. Work-up for the left flank pain began on an outpatient basis and included an intravenous pyelogram, an upper gastrointestinal series, abdominal and pelvic ultrasonography, thoracolumbar spine films, and a barium enema; all results were reported as normal. CT of the abdomen and pelvis revealed a large multiloculated fluid collection in the left psoas muscle without bony involvement. Results of a technetium diphosphonate bone scan were normal as well. A bronchoalveolar lavage specimen, obtained to exclude tuberculosis, remained negative for acid-fast bacilli. 
Purulent material obtained by CT-guided aspiration was found to be smear positive after both Ziehl-Neelsen and auramine staining. PCR detected DNA from nontuberculous mycobacteria. Culture by use of the BACTEC system (Becton Dickinson, Cockeysville, MD) revealed growth of $M$. xenopi, first identified by specific PCR and secondarily by biochemical testing and gas chromatography [3].

Antimycobacterial therapy with isoniazid, rifampin, ethambutol, and pyrazinamide was initiated. In vitro susceptibility testing that was performed on solid media by use of the proportion technique of Canetti showed resistance to isoniazid, ethambutol, pyrazinamide, and ethionamide. The organism was susceptible to ofloxacin, rifabutin, and amikacin.

Ofloxacin was added to the patient's therapeutic regimen when M. xenopi was identified. Two months later, because of the enlargement of the abscess, a drainage catheter was inserted, yielding $300 \mathrm{~mL}$ of purulent material. Auramine staining of this material again demonstrated acid-fast bacilli, but cultures remained negative. The abscess cavity was irrigated with povidone-iodine. Therapy with pyrazinamide and ofloxacin was discontinued, and ciprofloxacin was added to the therapeutic regimen.

A second percutaneous drainage with lavage was performed 1 month later because there was no improvement in the patient's condition; this procedure yielded $150 \mathrm{~mL}$ of purulent material. Acid-fast bacilli were not detected, by either direct examination or culture.

Medical treatment was continued for 18 months, with clinical improvement and biological normalization. CT performed 17 months after completion of therapy revealed a significant persistent loculated fluid collection, despite the patient's satisfactory clinical state.

Primary psoas muscle abscess is an uncommon infection and caused most often by infection due to Staphylococcus aureus. To our knowledge, this is the first description of a case of primary psoas muscle abscess caused by M. xenopi [2].

The portal of entry of the bacillus remains an enigma; repeated studies (radiographic and scintigraphic) failed to demonstrate a pulmonary, bone, or other source for the psoas muscle infection.

\section{Infection Due to Nocardia farcinica in a Woman with Chronic Granulomatous Disease}

Nocardiosis, an infection due to an aerobic actinomycete, has a pronounced tendency toward remission and exacerbation. The Nocardia asteroides complex comprises three species: $N$. aster-

Reprints or correspondence: Dr. C. A. P. Fijen, University of Amsterdam, Academic Medical Centre, Department of Medical Microbiology, L1-104, Meibergdreef 15, 1105 AZ Amsterdam, the Netherlands.

Clinical Infectious Diseases 1998;26:222-4

(C) 1998 by The University of Chicago. All rights reserved

$1058-4838 / 98 / 2601-0057 \$ 03.00$
PCR methods were very useful in that they allowed early detection of mycobacterial DNA and the determination of its nontuberculous mycobacterial origin. The specific PRC technique allowed M. xenopi identification within 24 hours after the culture became positive.

The optimal therapeutic regimen and duration of treatment for infection due to $M$. xenopi are not clearly defined. In vitro susceptibility tests of $M$. xenopi frequently show resistance to isoniazid, rifampin, pyrazinamide, and ethambutol. Nevertheless, these agents are recommended as the therapy of choice, given that previous studies have demonstrated a poor correlation between in vitro results and clinical responses [2-4]. The quinolones are an alternative treatment for infection due to $M$. xenopi.

Management of a large psoas muscle abscess requires appropriate antibiotic therapy (usually $18-24$ months), in conjunction with percutaneous drainage or open surgical drainage. In our patient, the percutaneous drainage and the antibiotic therapy may not have been completely successful because of the multiloculated nature of the abscess. We have no explanation for enlargement of the fluid collection in the context of microbiological cure and improvement in the patient's condition.

\section{Thierry Prigogine, Guy Stoffels, Maryse Fauville-Dufaux, Christine Trolin, and Christian Raftopoulos Free University of Brussels and Institut Pasteur, Brussels, Belgium}

\section{References}

1. Simor AE, Salit IE, Vellend H. The role of Mycobacterium xenopi in human disease. Am Rev Respir Dis 1984; 129:435-8.

2. Miller WC, Perkins MD, Richardson WJ, Sexton D. Pott's disease caused by Mycobacterium xenopi: case report and review. Clin Infect Dis 1994; 19:1024-8

3. Fauville-Dufaux M, Maes N, Severine E, et al. Rapid identification of Mycobacterium xenopi from bacterial colonies or "Bactec" culture by the polymerase chain reaction and a luminescent sandwich hybridization assay. Res Microbiol 1995; 146:349-56.

4. American Thoracic Society. Diagnosis and treatment of disease caused by nontuberculous mycobacteria. Am Rev Respir Dis 1990; 142:940-53. oides sensu stricto, Nocardia farcinica, and Nocardia nova [1]; these organisms are responsible for $>80 \%$ of cases of human nocardiosis $[1,2]$. Nocardiosis is found predominantly $(60 \%$ of cases) in individuals with a wide variety of immunocompromising diseases $[1,3]$. Chronic granulomatous disease (CGD) predisposes to infections at an early age with catalase-positive bacteria such as the Nocardia species [4]. The defect of the phagocytic nicotinamide adenine dinucleotide phosphate (NADPH)-oxidase complex in patients with CGD either is present in the membrane-bound cytochrome $b$ complex and is $\mathrm{X}$-linked inherited ( $60 \%$ of patients) or is due to autosomal inherited defects of cytosolic components $\mathrm{p} 47^{\text {phox }}$ (35\%), p67 $67^{\text {phox }}$ $(5 \%)$, or p $22^{\text {phox }}(2 \%-5 \%)$ [4]. Although $1.3 \%$ of the reported cases of nocardiosis involve patients with CGD [1], to our knowledge, infection due to $N$. farcinica in a patient with CGD has not been reported; we describe such a patient. 
A 56-year-old woman with CGD and a 1-month history of fever and a cough productive of greenish sputum failed to respond to treatment with erythromycin. She was admitted to the hospital. Her medical history included recurrent inguinal lymphadenitis, pulmonary sarcoidosis, and colitis. In 1988, she was treated for breast carcinoma. In 1994, mastitis due to infection with Aspergillus fumigatus was diagnosed, and she was treated with amphotericin B; at that time, therapy was changed to that with itraconazole because her renal function had deteriorated. CGD due to $\mathrm{p} 47^{\text {phox }}$ deficiency was diagnosed. Treatment for CGD with interferon and prophylaxis for infection with co-trimoxazole were discontinued because of side effects.

On admission to the hospital, the patient's temperature was $39^{\circ} \mathrm{C}$. Auscultation over the upper lobe of the right lung revealed the presence of fine crackles. The erythrocyte sedimentation rate $(71 \mathrm{~mm} / \mathrm{h})$ and the WBC count $\left(14.4 \times 10^{9} / \mathrm{L}\right.$ with left shift $)$ were elevated, and anemia was present (hemoglobin level, $42.5 \mathrm{~g} / \mathrm{dL}$ ). A chest radiograph and a chest CT scan revealed a cavernous lesion, $7 \mathrm{~cm}$ in diameter, in the right upper lobe of the lung (figure 1). Bronchoscopic examination revealed no abnormalities, but gram straining of the bronchoalveolar lavage fluid and biopsy specimens showed gram-positive, filamentous and branched bacteria, which were fluorescent with Uvitex 2B (R\&R, Kandern, Germany). With an assumed diagnosis of nocardiosis and consideration of the amphotericin $\mathrm{B}$-induced renal damage, iv cefotaxime (1 g q.i.d.) and imipenem (500 mg q.i.d.) were administered. The fever resolved, and, within 6 months, the pulmonary cavernous lesion resolved.

Aerobic incubation of the bronchoscopic specimens at $37^{\circ} \mathrm{C}$ for 4 days yielded folded, heaped, slightly orange colonies producing an aerial mycelium. The microorganism was partially acid-fast, was resistant to lysozyme, and produced urease and acid from glucose and rhamnose. $N$. farcinica was identified on the basis of negative decomposition of adenine, casein, xanthine, hypoxanthine, and tyrosine; equal growth at $35^{\circ} \mathrm{C}$ and $45^{\circ} \mathrm{C}$; opacification of Middlebrook agar; results of qualitative evaluation of cell-wall mycolic and amino acids; and saccharide cell content [5]. The strain was resistant to ampicillin, ticarcillin, cefoxitin, kanamycin, tobramycin, gentamicin, and erythromycin; moderately susceptible to cefamandole and cefotaxime; but susceptible to sulfonamides, amoxicillin/clavulanic acid, imipenem, and amikacin. Therapy with cefotaxime and imipenem was continued because of a favorable response with this regimen. After 6 weeks, the therapeutic regimen was changed to oral minocycline, $100 \mathrm{mg}$ b.i.d.

Specific characteristics of species within the $N$. asteroides complex include growth at $45^{\circ} \mathrm{C}$ for 3 days, growth on various nitrogen and carbon sources, and specific enzymatic activities; however, the organism may also be identified by analysis of antibiotic resistance patterns $[1,5]$. N. farcinica is resistant to tobramycin, cefamandole, and cefotaxime [3, 5-7].

The lungs, brain, and traumatic and postoperative wounds were the most common primary sites of infection due to $N$. farcinica among 65 cases, but the paranasal sinuses, the oral palate, and the eyes can also be involved [2, 3, 5-9]. Mouse studies demonstrate that $N$. farcinica is more virulent than $N$. asteroides [6]. More patients with $N$. farcinica infections [2, 3, 6-9] are immunocompromised $(70 \%)$ than are patients with $N$. asteroides infections [1]. $N$. farcinica has a greater tendency to disseminate [6] to the CNS

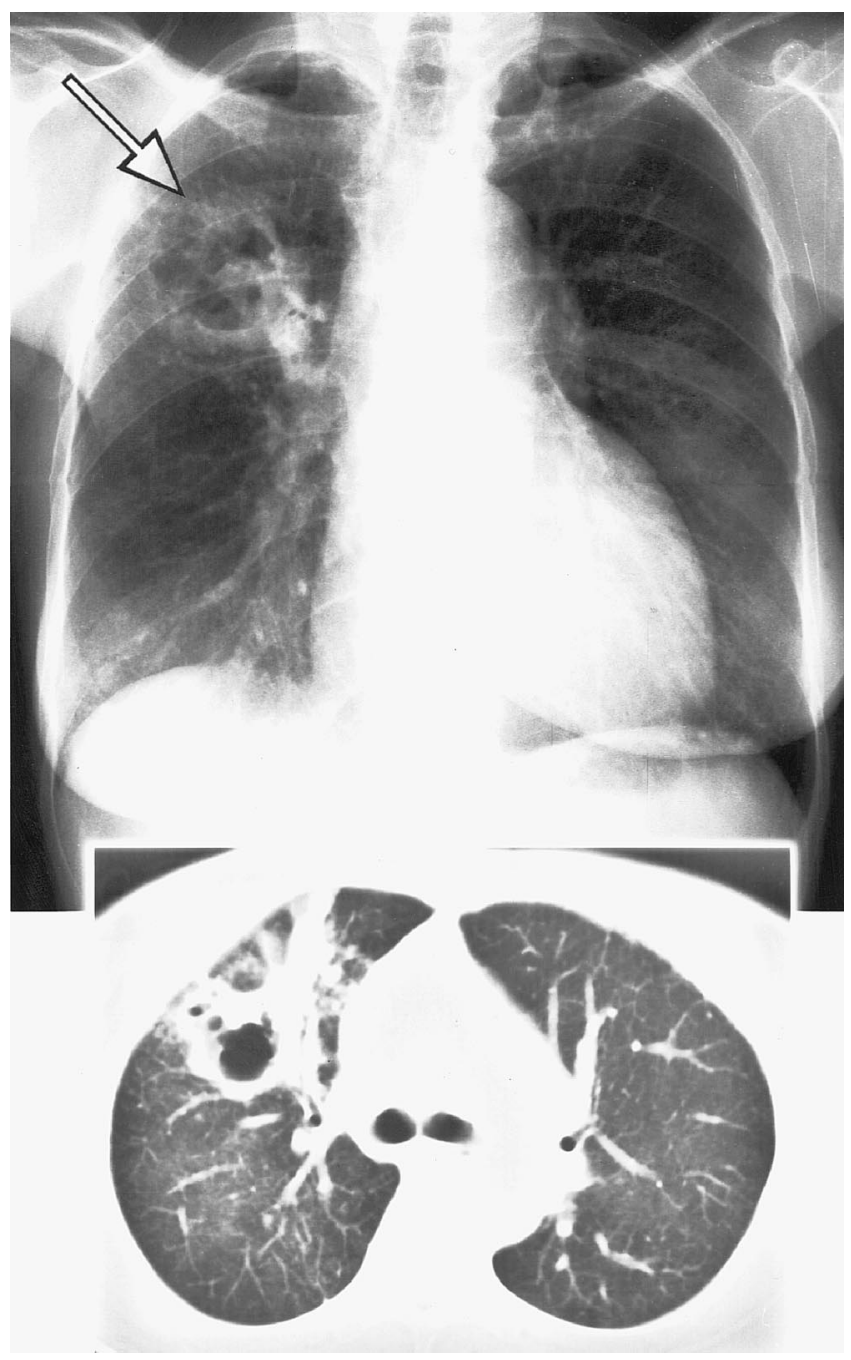

Figure 1. Radiograph and CT scan (insert) of the thorax of a patient with chronic granulomatous disease and infection due to Nocardia farcinica. A cavernous lesion developed 1 month after admission (arrow).

[3], but it also disseminates to the joints, kidneys, bones, and endocardium $[2,3,5,6]$.

In our patient, the primary lesion was located in the right lung. Lack of dissemination and the low number of infections in her youth may be due to the residual killing activity present in her granulocytes. Consistent with this hypothesis, a recent report described residual superoxide production of the granulocytes in seven of 11 adult CGD patients for whom the rate of infectious complications was low during youth [10].

Sulfonamides are still the treatment of choice for infections due to $N$. farcinica $[2,3]$. Good therapeutic results with monotherapy or various combinations of imipenem, amikacin, amoxicillin plus clavulanic acid, and minocycline have also been reported [2, 3]. Combinations of imipenem and amikacin or cefotaxime and imipenem are effective and synergistic against $N$. asteroides in the mouse model [3], but for $N$. farcinica, such data are not available. 
Neither are case-control studies comparing the efficacy of the various treatment regimens.

C. A. P. Fijen, J. Schrama, E. J. Kuijper, P. Boiron, W. Gerritsen, and P. Speelman Department of Medical Microbiology and Department of Internal Medicine/Infectious Diseases, Academic Medical Centre, University of Amsterdam, and Department of Hematology/Oncology, Anthoni van Leeuwenhoek Hospital, Amsterdam, the Netherlands; and Unite de Mycologie, National Center for Mycoses and Antifungal Agents, Institut Pasteur, Paris, France

\section{References}

1. Beaman BL, Beaman L. Nocardia species: host-parasite relationships. Clin Microbiol Rev 1994; 7:213-64.

2. Peters BR, Saubolle MA, Costantino JM. Disseminated and cerebral infection due to Nocardia farcinica: diagnosis by blood culture and cure with antibiotics alone. Clin Infect Dis 1996;23:1165-7.

\section{Neurosyphilis and Syphilitic Gumma of the Adrenal Gland}

Syphilitic gummas have been described in different body organs, but syphilis of the adrenal gland is rare; only two cases were reported in the first half of this century [1]. As far as we know, ours is the first case of syphilitic gumma of the adrenal gland to be reported in recent years.

A 66-year-old male was admitted to the hospital in 1996 with a 2-week history of abdominal pain and constipation and diminished vision in the right eye; he had had lethargy, polydipsia, and gait disturbance for several months.

On admission he was afebrile and had angular cheilosis and a small keratoid lesion at the right oral commissure. He was oriented $\times 3$, but his short-term memory was impaired. He had diminished central vision in the right eye, with minimal blurring of the disk margins on the right. He had mild upper-extremity weakness that was more pronounced on the left than on the right. His gait was broad based and mildly ataxic.

Laboratory studies revealed the following values: sodium, 137 $\mathrm{mEq} / \mathrm{L}$; potassium, $5.2 \mathrm{mEq} / \mathrm{L}$; chloride, $102 \mathrm{mEq} / \mathrm{L}$; thyroxine, $0.82 \mu \mathrm{g} / \mathrm{dh}$; and thyroid stimulating hormone, $33.86 \mu \mathrm{g} / \mathrm{dL}$. A test for thyroid antibodies was positive. The erythrocyte sedimentation rate was $140 \mathrm{~mm} / \mathrm{h}$. A CT scan of the abdomen showed a left adrenal mass with a central cystic area and a prominent right adrenal gland. MRI of the head showed ischemic changes. Therapy with thyroxine was started after admission. Six days later, the

This work was presented in part at the Annual Scientific Meeting of the New Jersey Chapter of the American College of Physicians held on 10-11 January 1997 at Long Branch, New Jersey.

Reprints or correspondence: Dr. Gary Gartenberg, Highland Park Medical Associates, 205 North Second Avenue, Highland Park, New Jersey 08904.

Clinical Infectious Diseases $1998 ; 26: 224-5$

(C) 1998 by The University of Chicago. All rights reserved

$1058-4838 / 98 / 2601-0058 \$ 03.00$
3. Beaman BL, Boiron P, Beaman L, Brownell GH, Schaal K, Gombert ME. Nocardia and nocardiosis. J Med Vet Mycol 1992;30(suppl 1): $317-31$.

4. Thrasher AJ, Keep NH, Wientjes F, Segal AW. Chronic granulomatous disease. Biochim Biophys Acta 1994; 1227:1-24.

5. Boiron P, Provost F, Dupont B. Laboratory methods for the diagnosis of nocardiosis. Paris: Institut Pasteur, 1993:88-126.

6. Schiff TA, McNeil MM, Brown JM. Cutaneous Nocardia farcinica infection in a nonimmunocompromised patient: case report and review. Clin Infect Dis 1993; 16:756-60.

7. Boiron P, Provost F, Chevrier G, Dupont B. Review of nocardial infections in France 1987 to 1990. Eur J Clin Microbiol Infect Dis 1992;11: 709-14.

8. Bani-Sadr F. Hamidou M, Raffi F, Chamoux C, Caillon J, Freland C. Aspects cliniques et bactériologiques des nocardioses, 9 observations. Presse Med 1995;24:1062-6.

9. Farina C, Boiron P, Goglio A, Provost F. Human nocardiosis in Northern Italy from 1982 to 1992 . Scand J Infect Dis 1995;27:23-7.

10. Liese JG, Jendrossek V, Jansson A, et al. Chronic granulomatous disease in adults. Lancet 1996; 347:220-3.

patient suddenly became somnolent. His vital signs were: temperature, $102.4^{\circ} \mathrm{F}$; pulse, $85 / \mathrm{min}$ and regular; and blood pressure, $84 / 44 \mathrm{~mm} \mathrm{Hg}$. He was resuscitated with intravenous fluids, hydrocortisone, and antibiotics. All cultures were negative. The cortisol level at time of collapse was $18 \mu \mathrm{g} / \mathrm{dL}[2,3]$, and the results of a cosyntropin test were normal.

Additional work-up revealed a rapid plasma reagin (RPR) titer of 1:8,192, and a serum fluorescent treponemal antibody (FTA) test was positive. Serology for IgG and IgM antibodies to Borrelia burgdorferi was positive, but PCR assays of blood and CSF were negative. Laboratory studies of the CSF showed a protein level of $96 \mathrm{mg} / \mathrm{dL}$, a total WBC count of $55 / \mathrm{mm}^{3}$ with $94 \%$ lymphocytes, and a glucose concentration of $54 \mathrm{mg} / \mathrm{dL}$ (serum glucose concentration, $100 \mathrm{mg} / \mathrm{dL}$ ). A CSF venereal disease research laboratory (VDRL) test was positive (titer, 1:16), and an FTA test of the CSF was positive. A test for antibodies to HIV was negative. The patient received penicillin $\mathrm{G}$ intravenously for 10 days. An ophthalmologist diagnosed right-eye ischemic optic neuropathy secondary to neurosyphilis.

Left adrenalectomy was performed, revealing a $3 \times 2 \times 1-\mathrm{cm}$ adrenal mass with multiple hemorrhages. Microscopic examination of the mass revealed focal areas of necrosis with inflammatory cells surrounded by fibrous tissue showing moderate lymphoplasmacytic infiltrate. A Warthin-Starry stain showed numerous spirochetes (typical of Treponema pallidum) within the necrotic areas, confirming a diagnosis of syphilitic gumma of the adrenal gland (figure 1). After the adrenalectomy was performed, the patient became lethargic; results of a repeated cosyntropin test were abnormal, consistent with adrenal insufficiency [4], and replacement therapy was started.

The clinical manifestations in our patient are consistent with neurosyphilis; the types of neurosyphilis commonly described are asymptomatic, meningeal, meningovascular, and parenchymatous, and there is often overlap among the types [5]. Our patient's manifestations were predominantly those of meningovascular syphilis, as manifested by memory impairment, weakness in his left upper extremity, and the ischemic optic neuropathy in association with 


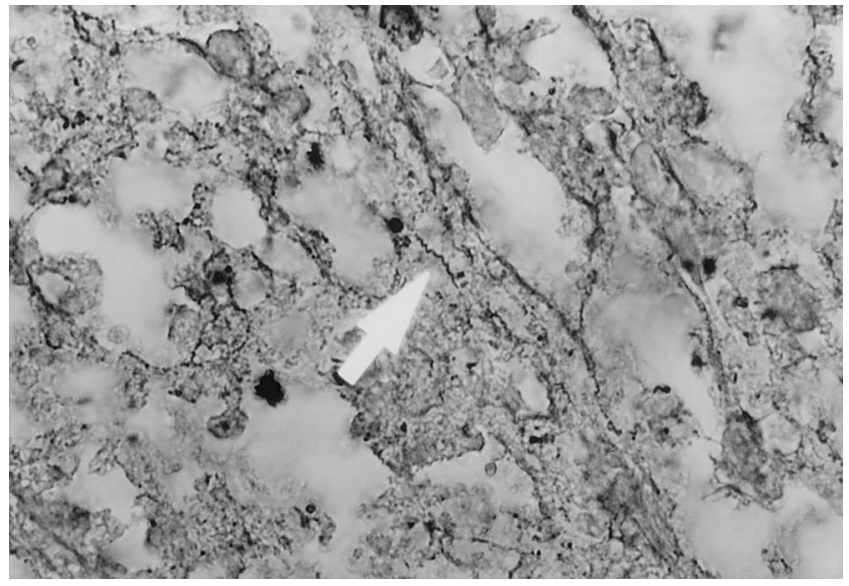

Figure 1. Warthin-Starry stain of adrenal tissue from a patient with a syphilitic gumma of the adrenal gland showing a spirochete (arrow) (original magnification, $\times 1,000$; oil immersion).

the MRI findings of ischemic changes in the brain. Neurosyphilis is often a presentation of tertiary syphilis, but neurosyphilis may also be seen in patients with secondary syphilis. The RPR titers in our patient were very high, suggestive of the secondary stage.

Gummatous ulceration may occur at the angles of the mouth [6]. When our patient's adrenal gland was found to contain a gumma, the previously biopsied oral commissure lesion was examined with Warthin-Starry stain and was found to contain spirochetes.

Following treatment with iv penicillin G, the patient's clinical status improved, and he became less confused. Four months later, repeated examination of the CSF showed $4 \mathrm{WBCs} / \mathrm{mm}^{3}$, a protein

\section{False-Positive Gen-Probe Direct Amplification Test in a Case of Mycobacterium avium Complex Infection}

Mycobacterial infection continues to be a significant disease, with a reported 8 million new cases of tuberculosis in 1990 and $>300,000$ cases attributable to HIV infection [1]. Despite new advances in nucleic acid technology, definitive diagnosis still relies primarily on microscopy and culture. Recent developments in the area of DNA and RNA amplification have allowed the rapid detection of mycobacterial nucleic acids directly in clinical samples. Although this new technology promises more rapid diagnosis than its standard counterparts, which depend on the slow growth of acid-fast bacilli (AFB), such a tool in its early stages should be used with discretion, especially when it is used as a tool for diagno-

Reprints or correspondence: Dr. Marcus J. Zervos, William Beaumont Hospital, 3601 West 13 Mile Road, Royal Oak, Michigan 48073.

Clinical Infectious Diseases 1998;26:225-6

(C) 1998 by The University of Chicago. All rights reserved.

$1058-4838 / 98 / 2601-0059 \$ 03.00$ level of $37 \mathrm{mg} / \mathrm{dL}$, and a glucose level of $54 \mathrm{mg} / \mathrm{dL}$; a CSF VDRL test was negative, and the serum RPR titer was 1:128.

Our patient's acute state of decompensation 6 days after admission was probably secondary to adrenal insufficiency precipitated by thyroxine therapy, and the subsequent abnormal cosyntropin test results obtained after adrenalectomy indicate syphilitic involvement of the remaining adrenal gland. Although syphilitic involvement of the adrenal gland was not listed as a cause of adrenal insufficiency in a recent review [7], this condition should be noted as a cause of adrenal insufficiency.

\section{Noel Ilogu, Paul Daidone, Todd Stefan, Ted Louie,} Steven Deak, and Gary Gartenberg

Department of Internal Medicine, St. Peters Medical Center/ Robert Wood Johnson Medical School, New Brunswick, New Jersey

\section{References}

1. Stokes JH, Beerman H, Ingraham NR. Modern clinical syphilology; diagnosis, treatment, and case study. 3rd ed. Philadelphia: W.B. Saunders, 1944: 1183.

2. Grinspoon SK, Bitter BMK. Laboratory assessment of adrenal insufficiency. J Clin Endocrinol Metab 1994; 79:923-31.

3. Vermes I, Beishnizen A, Hampsink RM, Haanen C. Dissociation of plasma adrenocorticotropin and cortisol levels in critically ill patients: possible role of endothelin and atrial natriuretic hormone. J Clin Endocrinol Metab $1995 ; 80: 1238-42$.

4. Werbel SS, Ober KP. Acute adrenal insufficiency. Endocrinol Metab Clin North Am 1993;22:303-28.

5. Hoeprich P, Jordan M, Ronald A. Infectious diseases - a treatise of infectious processes. 5th ed. Philadelphia: J.B. Lippincott, 1994:694-714.

6. Kampmeir RH. Essentials of syphilology. 3rd ed. Philadelphia: J.B. Lippincott, 1943:257.

7. Oelkers W. Adrenal Insufficiency. N Engl J Med 1996;335:1206-11. sis. We present a case that illustrates the use of DNA amplification that resulted in the false-positive detection of Mycobacterium tuberculosis in an HIV-positive patient for whom cultures of sputum and blood yielded only Mycobacterium avium (MAC).

A 38-year-old HIV-positive female with a history of nonHodgkins' lymphoma was admitted to the hospital in July 1996 with a 2-day history of pleuritic chest pain associated with fever, chills, and a productive cough yielding yellowish sputum; findings on a chest radiograph were normal. HIV infection had been diagnosed 1 month before admission, and she had no history of any AIDS-defining illnesses or any antibiotic or antiretroviral therapy. Her last total absolute lymphocyte cell count, obtained 1 month before, was $308 / \mathrm{mm}^{3}$, and her last CD4 lymphocyte count was $108 / \mathrm{mm}^{3}$.

During hospitalization, she remained febrile despite treatment with ticarcillin/clavulanate, vancomycin, and trimethoprimsulfamethoxazole. Blood and sputum were evaluated for mycobacterial infection, and one of four sputum samples was positive on auramine-rhodamine staining (6-10 bacilli per high-power field were detected). Samples were evaluated by using the rRNA amplification-based Gen-Probe Amplified Mycobacterium Tuberculosis Direct Test (AMTD) system (Gen-Probe, San Diego, CA). The 
AMTD yielded a value of 81,099 relative light units (RLU). According to the manufacturer's specification, values $\geqslant 30,000$ RLU are indicative of a positive test, thereby establishing the presence of M. tuberculosis. Although none of the initial or follow-up blood cultures ever yielded M. tuberculosis, they did, however, yield MAC. In addition, when the initial sputum sample used for the AMTD was cultured, it also yielded MAC.

Comparative DNA analyses of $M$. tuberculosis and MAC have exhibited a MAC gene (M122) that encodes an M. tuberculosis protein homologue displaying 78\% DNA sequence identity and $77 \%$ protein sequence identity [2]. It is possible that this nucleic acid similarity may be carried through to the rRNA level, so that amplification probes that use DNA intermediates (as this system does) may indiscriminately bind to this homologous MAC nucleotide sequence, and this binding may be responsible for the lowlevel false-positive value obtained in our case. This, however, is only speculation, as the exact mechanism of this false-positive value is undetermined.

The results of this case suggest that low-level AMTD values may be falsely positive due to the presence of MAC. In any case, despite a recent study of the Gen-Probe AMTD in which $100 \%$ sensitivity and $99.3 \%$ specificity were found [3], it is clear that this was not the case for the patient described above. Other investigations have reported similar observations [4]. Low-level positive

\section{The Role of Phagocytic Respiratory Burst in Host Defense Against Mycobacterium tuberculosis}

Tuberculosis is a major cause of morbidity and mortality worldwide [1]; however, the mechanisms by which host phagocytic cells defend against Mycobacterium tuberculosis remain obscure. Chan et al. implicated reactive nitrogen intermediates (RNI) as the principal mechanism responsible for the destruction of $M$. tuberculosis by murine macrophages [2]. Further, by demonstrating that the oxygen radical scavengers, superoxide dismutase (SOD) and catalase, have no effect on the antimycobacterial activity of macrophages, these authors suggest that the involvement of reactive oxygen intermediates (ROI) in the killing of M. tuberculosis is unlikely [2]. Patients with chronic granulomatous disease (CGD) have a defect in the nicotinamide adenine dinucleotide phosphate (NADPH) oxidase pathway that renders neutrophils incapable of generating oxygen radicals. Jones et al. demonstrated that CGD neutrophils are as capable of decreasing the viability of $M$. tuberculosis as are normal neutrophils, thereby concluding that the killing of $M$. tuberculosis is independent of the oxygen metabolic burst [3]. In addition, M. tuberculosis has not been described as a major pathogen in patients with CGD in the United States [4]. Despite this conventional view, we have clinical evidence that the generation of

\footnotetext{
Financial support: the CRCG of the University of Hong Kong.

Reprints or correspondence: Dr. Y. L. Lau, Department of Paediatrics, Queen Mary Hospital, Pokfulam Road, Hong Kong.

Clinical Infectious Diseases 1998;26:226-7

(C) 1998 by The University of Chicago. All rights reserved. $1058-4838 / 98 / 2601-0060 \$ 03.00$
}

AMTD values of 30,000-100,000 RLU, especially in the presence of MAC, should therefore be interpreted with extreme caution.

Eileen D. Javellana and Marcus J. Zervos

Department of Medicine, William Beaumont Hospital, and Wayne State University School of Medicine, Detroit, Michigan

\section{References}

1. Kochi A. The global tuberculosis situation and the new control strategy of the World Health Organization. Tubercle 1991;28:1-6.

2. Nair J, Rouse DA, Morris SL. Nucleotide sequence analysis and serologic characterization of the Mycobacterium intracellulare homologue of the Mycobacterium tuberculosis $19 \mathrm{kDa}$ antigen. Molec Microbiol 1992;6: 1431-9.

3. Ichiyama S, Iinuma Y, Tawada Y, et al. Evaluation of Gen-Probe Amplified Mycobacterium tuberculosis Direct Test and Roche PCR-Microwell Plate Hybridization Method (AMPLICOR MYCOBACTERIUM) for direct detection of mycobacteria. J Clin Microbiol 1996;34:130-3.

4. Jorgensen JH, Paxson R, Patterson JE, Patterson TF. False-positive genprobe Direct $M$. tuberculosis amplification tests in patients with pulmonary $M$. kansasii infection [abstract LB19]. In: Program and abstracts of the 36th Interscience Conference on Antimicrobial Agents and Chemotherapy (New Orleans). Washington, DC: American Society for Microbiology, 1996.

ROIs by phagocytic respiratory burst may play a role in the defense of the host against M. tuberculosis.

Between January 1988 and December 1996, we diagnosed CGD in 11 young Chinese males on the basis of the absence of reduction of nitroblue tetrazolium. The clinical features of six of these patients have been reported previously [5]. Mutations of the gp9 $1^{\text {phox }}$ gene were defined for seven of the eight patients who are alive, thereby establishing the diagnosis of X-linked CGD [6]. Our review of the clinical courses of these 11 patients represents a total observation period of 75 patient-years. Three of the 11 patients died at $1.4,0.4$, and 0.3 years of age. Two died of infection due to Pseudomonas species, and one died of infection due to Escherichia coli. The mean age of the remaining eight patients was 9 years (range, 1.9-21.4 years). Of the eight survivors, six had recurrent, intractable tuberculosis (table 1).

The index case for patients 1 and 2, who are brothers, was their father, who had smear-positive pulmonary tuberculosis. Patient 2 also had multiple splenic abscesses, most likely of tuberculous origin, at the time of his second episode of pulmonary tuberculosis. Resolution of the splenic abscesses was more rapid than that of the pulmonary lesions, for which right middle lobectomy was eventually required. At the time the cases were reported, the patients had been receiving anti-tuberculous treatment for $>3$ years and IFN- $\gamma$ for the last few months. The M. tuberculosis isolate from patient 1 was susceptible to first-line anti-tuberculous agents. However, the pulmonary lesions of the two brothers responded poorly to treatment; there were persistent changes evident on chest radiographs. Patients 3, 4, and 5 had recurrent tuberculous infections that responded to treatment for 9 months to 1 year with standard anti-tuberculous regimens. Shadows evident on chest radiographs were slow to resolve, suggesting an exaggerated inflammatory response. Patient 5 also presented with calcified left axillary lymph node at 6 months of age, most likely due to vaccination with BCG, 
Table 1. Characteristics of tuberculous infections in six patients with chronic granulomatous disease.

\begin{tabular}{|c|c|c|c|}
\hline Patient no. & Age (y) & Site involved & Diagnostic methods, results \\
\hline \multirow[t]{2}{*}{1} & 6.1 & Lung & $\mathrm{CR}, \mathrm{MT}$ \\
\hline & 7.3 & Lung & $\begin{array}{l}\text { CR; buffy coat culture yielded Mycobacterium } \\
\text { tuberculosis }\end{array}$ \\
\hline \multirow[t]{2}{*}{2} & 4.7 & Lung & $\mathrm{CR}, \mathrm{MT}$ \\
\hline & 7.7 & Lung & $\begin{array}{l}\text { CR, MT; lobectomy specimen showed } \\
\text { granulomatous histology }\end{array}$ \\
\hline \multirow[t]{2}{*}{3} & 3.3 & Axillary lymph node & AFB seen on excision biopsy \\
\hline & 5.0 & Lung & $\begin{array}{l}\text { CR; gastric aspirate culture yielded } \\
\text { M. tuberculosis }\end{array}$ \\
\hline \multirow[t]{2}{*}{4} & 7.3 & Lung & $\mathrm{CR}, \mathrm{MT}$ \\
\hline & 9.8 & Lung & $\begin{array}{l}\text { CR; AFB seen in bronchoalveolar lavage } \\
\text { specimen }\end{array}$ \\
\hline \multirow[t]{2}{*}{5} & 1.5 & Lung & $\mathrm{CR}, \mathrm{MT}$ \\
\hline & 3.3 & Lung & $\mathrm{CR}, \mathrm{MT}$ \\
\hline \multirow[t]{3}{*}{6} & 7.5 & Lung & $\begin{array}{l}\text { CR; gastric aspirate culture yielded } \\
\text { M. tuberculosis }\end{array}$ \\
\hline & 17 & Lung & CR; sputum culture yielded M. tuberculosis \\
\hline & 21 & Cervical lymph node & AFB seen on biopsy \\
\hline
\end{tabular}

NOTE. $\quad \mathrm{AFB}=$ acid-fast bacilli; $\mathrm{CR}=$ chest radiograph; $\mathrm{MT}=$ Mantoux test .

which is administered to all infants born in Hong Kong. Patient 6 , who is now $>20$ years old, had three episodes of tuberculous infections that responded only to prolonged anti-tuberculous treatment. The severity and recurrent nature of their tuberculous conditions suggest that the ability to destroy M. tuberculosis may be impaired in patients with CGD.

In recent years, the annual incidence of tuberculosis in Hong Kong has been $\sim 100$ cases per 100,000 population [7]; however, the annual incidence among our patients with CGD was 13 episodes over 75 patient-years (i.e., 17,333 cases per 100,000 population), which is $>170$ times that for the general population. Tuberculosis associated with CGD is rarely reported in the United States; the basis for this difference is unclear but may be the low level of exposure to tuberculosis in the general population.

The role of phagocytic respiratory burst in host defense against M. tuberculosis is further supported by recent studies in which the gene knock-out mouse model of X-linked CGD was used [8]. This mouse strain has increased susceptibility to infection, not only with Staphylococcus aureus and Aspergillus fumigatus, but also to infection with M. tuberculosis [9]. After intravenous inoculum with viable tubercle bacilli, there were increased $M$. tuberculosis counts, greater cellular infiltration, and increased numbers of granulomas in the lungs of the CGD mice as compared to normal mice. However, this increased susceptibility appeared to be localized only to the lungs of the CGD mice; there were no differences between the livers and spleens of the CGD mice and those of the normal mice after inoculation. This experimental observation is consistent with the clinical observation that M. tuberculosis caused persistent infection and chronic exaggerated inflammation in the lung but not in other organs, such as the spleen, in our patients with CGD.

Our clinical observation is unique in that the patients with a diagnosis of CGD live in an area where the incidence of tuberculo- sis is high; this combination of events allows us to infer that phagocytic respiratory burst plays a role in host defense against M. tuberculosis.

\author{
Y. L. Lau, G. C. F. Chan, S. Y. Ha, Y. F. Hui, \\ and K. Y. Yuen \\ Departments of Paediatrics and Microbiology, \\ University of Hong Kong, Queen Mary Hospital, Hong Kong
}

\section{References}

1. From what will we die in 2020? [editorial]. Lancet 1997;349:1263.

2. Chan J, Xing Y, Magliozzo RS, Bloom BR. Killing of virulent M. tuberculosis by reactive nitrogen intermediates produced by activated murine macrophages. J Exp Med 1992;4:1111-22.

3. Jones GS, Amirault HJ, Andersen BR. Killing of M. tuberculosis by neutrophils: a nonoxidative process. J Infect Dis 1990;162:700-4.

4. Quie PG, Mills EL, Roberts RL, Noya FJD. Disorders of the polymorphonuclear phagocytic system. In: Stiehm ER, ed. Immunologic disorders in infants and children. Philadelphia: WB Saunders, 1996:453-9.

5. Lau YL, Wong SN, Lawton WM, Chow CB. Chronic granulomatous disease: a different pattern in Hong Kong? J Paediatr Child Health 1991; 27:235-9.

6. Hui YF, Chan SY, Lau YL. Identification of mutations in seven Chinese patients with X-linked chronic granulomatous disease. Blood 1996;88: 4021-8.

7. Annual Report 1994/1995. Hong Kong: Department of Health, 1995:68.

8. Pollock JD, Williams DA, Gifford MAC, et al. Mouse model of X-linked chronic granulomatous disease, an inherited defect in phagocyte superoxide production. Nature Genetics 1995;9:202-9.

9. Adams LB, Diauer MC, Morganstern D, Krahenbuhl. Phagocytic burst oxidase plays a role in the host response to Mycobacterium tuberculosis [abstract no. U-29]. In: Program and abstracts of the 97th General Meeting of the American Society for Microbiology. Washington, DC: American Society for Microbiology, 1997:548. 